\title{
EAA Meeting Abstracts, September 2000, Paris
}

The senior author of each article has confirmed that the ethical aspects of these studies have been approved (a) for clinical studies by the Institution or an Ethics Committee and, if applicable, that informed patient consent has been obtained, (b) for experimental studies, involving the use of animals, by the institution and that the animals have been treated according to good practice.

\section{ABSTRACT NO. 1}

Effects of hypertonic hydroxyethylstarch solution (HHES) on hormone release in aortic surgery

M. Ragaller*, A. Strecker†, M. Menschikowskie*, W. Segiet†, M. Müller*, K. Ellingerł and D. M. Albrecht*

*Department of Anaesthesia University Hospital TU-Dresden, †Theresien Hospital, †University Hospital Mannheim, Germany

Introduction Infusion of hypertonic colloidal solution leads to fast resuscitation in haemorrhagic shock (small volume resuscitation). However, the influence on hormones of systemic fluid regulation has been poorly investigated. It was the aim of this study to analyse the effects of a hypertonic HES-solution on plasma levels of atrial natriuretic factor (ANF), renin $(R)$ and aldosterone $(A)$ in humans undergoing aortic surgery receiving a hypertonic colloidal solution for treatment of declamping shock.

Methods After approval by the local ethical committee, 17 patients (ASA < 3) scheduled for aortic aneurysm repair were enrolled in this double-blinded, randomized and controlled study. After induction of anaesthesia, the individual best wedge/cardiac output relation was assessed. After aortic declamping either $7.2 \% \mathrm{NaCl} / \mathrm{HES} 6 \%(n=11)$ or $0.9 \% \mathrm{NaCl} / \mathrm{HES} 6 \%$ ( $n=$ 6) were administrated in boluses of $100 \mathrm{~mL}$ to achieve best wedge again. Haemodynamic parameters, fluid balance and hormone levels were investigated. Data were analysed by Wilcoxon and $U$-test $(P<0.05)$.

Results The groups did not differ in haemodynamic parameters during the whole observation period. The amount of fluid to achieve best wedge was significantly lower in the hypertonic group $\left(2.3 \mathrm{~mL} \mathrm{~kg}^{-1}\right.$ HHES vs. $3.7 \mathrm{~mL} \mathrm{~kg}^{-1} \mathrm{HES}$ ). ANF increased after HHES compared with control $(P<0.05)$. Renin was increased during surgery and stayed significantly elevated in the control group $(P<0.01)$ up to the end of surgery whereas aldosterone did not change throughout surgery.

Conclusion After declamping, less hypertonic fluid was necessary to restore the best wedge to $\mathrm{CO}$ relation. Fluid resuscitation using HHES lead to a reduction of renin release compared with controls. ANF release may be related to increased sodium levels.

\section{ABSTRACT NO. 2}

In vitro investigation of myocardial contraction under the influence of xenon

S. Schroth*, U. Schotten†, O. Alkanoglu*, M. ReyleHahn*, P. Hanrath† and R. Rossaint*

*Department of Anesthesiology, University Hospital Aachen, Germany, and $\uparrow$ Department of Cardiology, University Hospital Aachen, Germany

Introduction Volatile anaesthetics such as halothane or isoflurane show myocardial depressant sideeffects. Xenon is a new anaesthetic agent with only mild cardiovascular side-effects in vivo. We investigated the influence of $65 \%$ xenon $(\mathrm{Xe})$ on baseline myocardial contractility and inotropic stimuli such as rising pacing frequencies and reaction to high calcium in isolated guinea pig ventricular muscle bundles.

Methods Thin ventricular muscle bundles (mean diameter $0.4-0.45 \mathrm{~mm}$ ) were superfused with buffer medium equilibrated with $65 \% \mathrm{Xe}$ and $35 \% \quad \mathrm{O}_{2}$ at $30^{\circ} \mathrm{C}$. Control muscles were superfused with buffer equilibrated with either $100 \% \mathrm{O}_{2}$ or a mixture of $35 \%$ $\mathrm{O}_{2}$ in $65 \% \mathrm{~N}_{2}$. Maximum contractile force and time for contraction and relaxation were continuously measured during xenon exposure for $30 \mathrm{~min}$, at rising pacing frequencies $(0.5-2 \mathrm{~Hz})$ and after calcium application (10.8 mmol). 
Results Under the influence of $65 \%$ xenon, neither the amplitude of contraction nor the time for contraction and relaxation were changed. The reaction to $10.8 \mathrm{mmol}$ calcium and to rising pacing frequencies (Fig. 1) did not differ between the muscles exposed to $\mathrm{Xe}$ and the control muscles.

Conclusion Xenon does not alter myocardial contractility and reaction to major inotropic stimuli such as calcium application or rising frequency in isolated guinea pig ventricular muscle bundles.

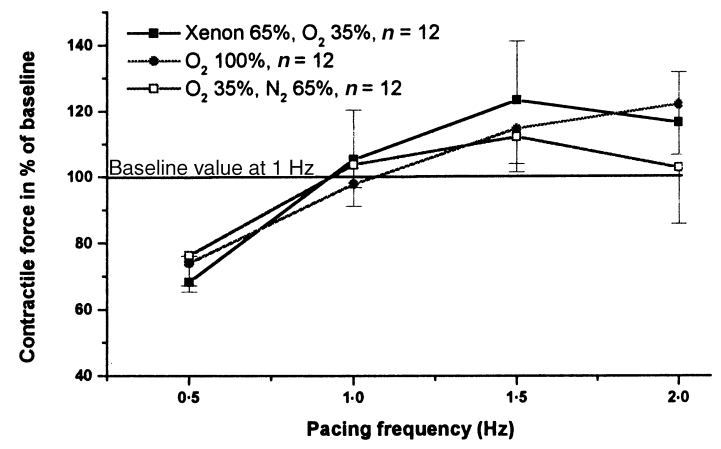

Fig. 1. Force-frequency relation under the influence of xenon.

ABSTRACT NO. 3

Low-dose administration of prostaglandin E1 maintains residual hepatic tissue blood flow during hepatectomy

Yoshito Shiraishi*, Jun-ichiro Yokoyama*, Kazuyuki Atsumi*, Kazuko Momose*, Naoshi Sato*, Naoko Yamaguchi*, Noriyuki Oba†, Yoshihiro Hiramatsu† and Kazushige Toyama $\dagger$ *Department of Surgery, †Department of Anaesthesiology, Shizuoka General Hospital, Japan

Introduction Tissue blood flow during anaesthesia is reported to be maintained when prostaglandin E1 (PGE1) is administered in low doses. In a previous study [1], we showed that low-dose administration of prostaglandin E1 maintained hepatic and renal function following radical surgery for oesophageal cancer. We investigated the relationship between changes in hepatic tissue blood flow during hepatectomy and the low-dose administration of PGE1.

Methods Subjects were 20 patients who underwent hepatectomy at the Shizuoka General Hospital (Japan) over a six-month period between July and December 1999. Patients with a massive haemorrhage were excluded from the present study. There were 14 men and six women with an average age of 60 years. On average, they weighed $60 \mathrm{~kg}$, and were $162 \mathrm{~cm}$ tall. The average duration of surgery was $6 \mathrm{~h}$ and $48 \mathrm{~min}$.

After laparotomy, the amount of hepatic tissue blood flow through the left and right sides was measured using a laser blood flowmeter (control). At the beginning of hepatectomy, $0.02 \mu \mathrm{g} \mathrm{kg}^{-1} \mathrm{~min}^{-1}$ of PGE1 was administered, and left and right hepatic tissue blood flow were measured 30,60 , and $120 \mathrm{~min}$ after the start of PGE1 administration. Also, $125 \mathrm{mg}$ of Solu-Medrol $^{(m)}$ was administered to suppress the postoperative release of cytokines, and $3 \mu \mathrm{g} \mathrm{kg}^{-1}$ $\min ^{-1}$ of dopamine to maintain renal blood flow during surgery. By measuring left and right hepatic tissue blood flow, changes in hepatic blood flow in the resected and residual sides were compared. After ANOVA, intergroup and intragroup analyses were performed using Student's $t$-test (significance level: 1\%).

Results When compared with the control value, residual hepatic blood flow slightly decreased to $91 \%$ at the start of hepatectomy, increased to $119 \%$ after 30 min from the start of PGE1 administration, and slightly decreased again to $83 \% 60 \mathrm{~min}$ after the start of PGE 1 administration. Nevertheless, there were no statistically significant changes. Thus, hepatic tissue blood flow was fairly well maintained, and it recovered to $98 \%$ of the control value $120 \mathrm{~min}$ after the start of PGE1 administration. Hepatic blood flow in the resected side at the start of hepatectomy, and 30 , 60 , and $120 \mathrm{~min}$ after the start of PGE1 administration was $75,84,62$, and 70, respectively (the last two values being significant decreases: $P<0.05)$.

Conclusion Low-dose administration of prostaglandin E1 was effective in maintaining residual hepatic tissue blood flow during invasive surgery. Even though the flow in the resected side decreased at the start of hepatectomy, it transiently increased $30 \mathrm{~min}$ after the start of PGE1 administration. Low-dose administration of prostaglandin E1 was useful in maintaining residual hepatic blood flow during hepatectomy. 


\section{Reference}

1 Shiraishi $Y$ et al. Prostaglandin E1 improves the long-term outcome of the hepatic and renal functions after radical surgery of esophageal cancer. Anesthesiology 1998; 89 (Suppl.): A193.

\section{ABSTRACT NO. 4}

Computer-assisted protocol for administration of low-dose protamine in heparin reversal after coronary bypass

P. Yannakopoulos, M. Tsitsika, R. Sfyra, M. Efthymiadou and E. Kammihali

Evangelismos Medical Hospital, Athens, Greece

Introduction The aim of this study was to evaluate the efficacy of a computer assisted algorithm for the calculation of protamine needed for heparin reversal.

Methods We studied 20 ASA III patients undergoing cardiopulmonary bypass for open heart surgery, excluding patients receiving anticoagulants or with coagulation disorders, haematological, renal or liver disease, sepsis, malignant disease, recent myocardial infarction, thromboembolism and transplantation. The patients were randomly assigned to two groups, $A$ and $B$. In group $A$, patients received an initial protamine dose equal to the amount of heparin given during coronary bypass (fixed ratio of $1: 1$ ). In group $B$, patients received a protamine dose equal in $\mathrm{mg}$ to the computer calculated amount of heparin remaining in the plasma. We assumed prevalence of a first order elimination rate of heparin. The activated clotting time (ACT) value was measured in both groups during the immediate preoperative period and $10 \mathrm{~min}$ after protamine administration. For each group we compared the preoperative and postprotamine ACT values. We also evaluated the total blood loss after the termination of the operation and up to $24 \mathrm{~h}$. In both groups a titrated supplemental dose of protamine was given if the ACT was prolonged.

Results The mean total dose of heparin was $347.5 \pm$ $60.8 \mathrm{mg}$ in group $\mathrm{A}$ and $351 \pm 68.64 \mathrm{mg}$ in group $\mathrm{B}(P$ $=0.9$ ); the mean total dose of protamine was $510 \pm$ $51.64 \mathrm{mg}$ in group $A$ and $148 \pm 48.29 \mathrm{mg}$ in group $B(P$ $=0.000$ ). The heparin to protamine ratio was $1: 1-1: 2$ (means 1:1.5) in group $A$, whereas in group $B: 1: 0.24-$
1:0.56 (means 1:0.43, $P=0.000$ ). Preoperative ACT values were $120.9 \pm 10.46 \mathrm{~s}$ in group $A$ and $121.8 \pm$ $13.82 \mathrm{~s}$ in group $\mathrm{B}(P=0.86)$. Postprotamine ACT values were $130 \pm 20 \mathrm{~s}$ in group $A$ and $110 \pm 9.1 \mathrm{~s}$ in group $\mathrm{B}(P=0.024)$ The amount of protamine calculated using the algorithm succeeded in normalizing the ACT value in all cases, even though the mean heparin to protamine ratio was much less than 1:1. Mean postoperative blood losses during the first $24 \mathrm{~h}$ were $720 \pm 532 \mathrm{~mL}$ in group $A$ and $505 \pm 279.32 \mathrm{~mL}$ in group $\mathrm{B}(P=0.32)$.

Conclusion In our study a significantly less than 1:1 heparin to protamine ratio (1:0.43) appears to normalize the ACT values indicating that previous protocols utilizing ratios 1:1 or more, probably result in excessive protamine administration.

\section{ABSTRACT NO. 5}

\section{Perioperative transnasal transoesophageal echocar- diography}

P. Zimmermann, C. A. Greim, H. Trautner, K. Kramer and N. Roewer

Department of Anaesthesiology, University of Würzburg Medical Center, Würzburg, Germany

Introduction Our hypothesis was that a new, miniaturized transoesophageal echocardiography (TOE) probe $[1,2]$ could be introduced transnasally in awake patients prior to general anaesthesia and that mask ventilation and orotracheal intubation could be performed while continuously monitoring cardiac function during anaesthesia induction.

Methods In 25 consecutive patients (ASA 1 and 2), a prototype transnasal TOE probe (Hewlett Packard, Andover, MA, USA) was introduced transnasally after local anaesthesia of the nasopharynx and advanced to the transgastric position. After obtaining a transverse plane image of the left ventricle (LV) at the level of the papillary muscles, anaesthesia was induced. Mask ventilation and intubation conditions were graded as good, moderate or poor by the resident performing the anaesthesia. Echo images during induction were recorded on tape for off-line analysis of image quality.

Results The transnasal TOE probe could be introduced in four patients under local anaesthesia alone 
and in additional 11 patients using a combination of local anaesthesia and mild sedation. In one case, the probe could not be inserted due to patient discomfort. Haemodynamic variables did not change significantly during insertion, mucosal bleeding was not seen, mask ventilation and intubation conditions were rated as good or moderate in all patients and there was no case of regurgitation of gastric contents. Two-dimensional echo image quality of the LV during induction of anaesthesia was good or acceptable in 15 of 16 patients. In one patient the lateral endocardial border could not be visualized.

Conclusion Transnasal TOE can safely be used for cardiac monitoring during induction of anaesthesia.

\section{References}

1 Spencer KT, Krauss D, Thurn J et al. Transnasal transesophageal echocardiography. J Am Soc Echocardiogr 1997; 10: 728-737.

2 Greim CA, Brederlan J, Belke C, Rowewer N. Early clinical results with transnasal esphageal echocardiography. Anaesthesist 1998; 47: 111-115.

\section{ABSTRACT NO. 6}

Halothane anaesthesia attenuates immune response in rats peripheral microcirculation after global ischaemia associated with cardiac arrest

K. Kusza, W. Jurczyk, M. Błaszyk and M. Siemionow Karol Marcinkowski Medical School of Sciences, Department of Anaesthesiology, Poznań, Poland

Introduction Several investigators have studied ischaemic brain injury after complete ischaemia, but the peripheral microcirculation response to global ischaemia under general anaesthesia has not been reported.

Methods Twelve male Sprague-Dawley rats were studied in two experimental groups. Group 1 cardiac arrest under halothane anaesthesia $(n=6)$ : Following induction of anaesthesia with pentobarbital $(40 \mathrm{mg}$ $\mathrm{kg}^{-1}$ i.p.) the trachea was intubated and the lungs ventilated with $1 \mathrm{MAC}$ of halothane and oxygen $\left(\mathrm{FiO}_{2}\right.$ =0.35). Group II cardiac arrest under isoflurane anaesthesia ( $n=6)$ : After induction as above, lung ventilation with 1 MAC of isoflurane with oxygen $\left(\mathrm{FiO}_{2}=0.35\right)$ was maintained. In both groups the cremaster muscle was isolated as a flap and prepared for intravital microscopic study. The following mea- surements were made at the microcirculatory lymphocytes activation (rolling, adherent and transmigrating in postcapillary venules). Global ischaemia by the Korpaczew method lasting $5 \mathrm{~min}$ under $1 \mathrm{MAC}$ halothane or $1 \mathrm{MAC}$ isoflurane was performed. Following efficacious resuscitation, the above variables were evaluated at one-hour time intervals $30 \mathrm{~min}$ after resuscitation.

Results Directly following resuscitation increased numbers of rolling and sticking lymphocytes were found in the halothane and isoflurane groups (111\%) and $(329 \%)$ when compared with baseline values. The most striking findings were increased lymphocytes rollers (179\%) and stickers $(226 \%)$ in the last hour of observation in the isoflurane group compared to the halothane group ( $P<0.01$ ).

Conclusion This study has shown that anaesthetics directly influence peripheral microcirculatory lymphocyte activation. One-MAC halothane anaesthesia attenuates immune responses to $5 \mathrm{~min}$ of global ischaemia by significantly decreased the number of activating lymphocytes.

\section{ABSTRACT NO. 7}

Cutaneous vasodilatation after intravenous anaesthetics: comparative study between propofol, thiopental and etomidate

J. Gonzalez-de-Zárate, A. Olmos, J. C. Alvarez, BL. Olmos and R. Muñoz

Clinic University Hospital, Department of Anaesthesia, University of Valladolid, Spain

Introduction Anaesthesia induction (Al) results in cutaneous vasodilatation and warming of the skin. This event is relating to hypothermia of redistribution. The aim of this study was to compare the degree of cutaneous vasodilatation caused by propofol, thiopental and etomidate.

Methods Sixty consenting ASA-1 adult patients, scheduled for elective surgery under general anaesthesia were randomized to three groups according to the i.v. anaesthetic induction (Al) agent used. G-1: propofol (O) (3 $\left.\mathrm{mg} \mathrm{kg}^{-1}, n=20\right)$; G-2: thiopental (O) (5 $\left.\mathrm{mg} \mathrm{kg}^{-1}, n=20\right)$; G-3: etomidate $(\square)\left(0.3 \mathrm{mg} \mathrm{kg}^{-1}, n\right.$ $=20)$. All patients received fentanyl $(0.1 \mathrm{mg})$ and vecuronium $\left(0.1 \mathrm{mg} \mathrm{kg}^{-1}\right)$. Anaesthesia was maintained with $\mathrm{N}_{2} \mathrm{O} / \mathrm{O}_{2}$ and fentanyl $0.1 \mathrm{mg}$ at the 10 th minute. Cutaneous vasodilatation was assessed by 
digital photoplethysmography (DPh). Fingertip and core temperatures were measured before, 5, 10, 15 and $20 \mathrm{~min}$ after Al. Statistical analysis was performed with ANOVA for repeated measures and Scheffe's test ( $P<0.05$ ).

Results Fingertip temperatures and DPh wave amplitudes increased $6-7^{\circ} \mathrm{C}^{*}$ and $6.9-9.7 \mathrm{mV} / \mathrm{N}^{*}$ in $\mathrm{G}-1$ and 2 (respectively), while both variables increased in G-3 after $10 \mathrm{~min}$ (Fig. 1).

Conclusion Fingertip vasodilatation after anaesthesia induction with propofol or thiopental was higher than etomidate. It could be related with sympathetic inhibition induced by each anaesthetic agent and the opening of thermoregulatory arteriovenous anastomoses.

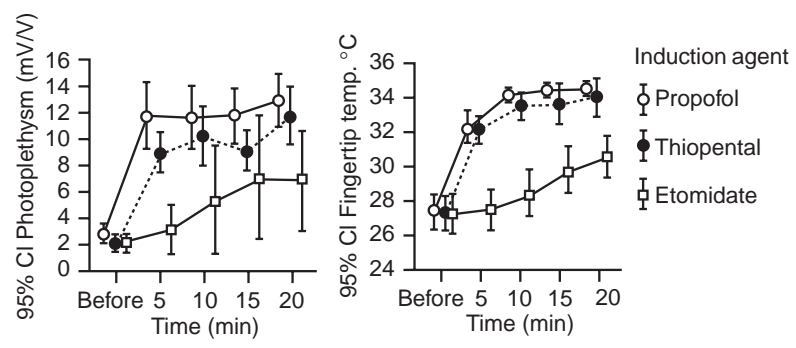

Fig. 1. Vasodilation with different induction agents.

ABSTRACT NO. 8

Effects of volatile anaesthetics on ryanodine-treated ventricular myocardium

P. R. Housmans and A. E. Bartunek

Mayo Foundation, Rochester, MN 55905, USA

Introduction Halothane, enflurane, isoflurane and sevoflurane depress myocardial contractility by decreasing trans-sarcolemmal $\mathrm{Ca}^{2+}$ influx, $\mathrm{Ca}^{2+}$ release from the sarcoplasmic reticulum (SR), and $\mathrm{Ca}^{2+}$ sensitivity of the contractile proteins. The aim of this study was to assess the relative functional impact of volatile anaesthetics on trans-sarcolemmal influx and contractility in conditions where contributions of $\mathrm{SR}$ release are minimized by pretreatment with ryanodine.
Methods After institutional approval, the right ventricular papillary muscles $(n=20)$ of ferrets were exposed to ryanodine $10^{-6} \mathrm{~mol}$ and then to incremental concentrations of either halothane, enflurane, isoflurane or sevoflurane from 0 to $1.5 \mathrm{MAC}$ in 0.5 MAC increments.

Results Each anaesthetic decreased contractility, the time to peak force and the time to half isometric relaxation in a reversible, concentration-dependent manner with no differences between halothane, isoflurane and sevoflurane. Enflurane depressed force more than the other anaesthetics (Fig. 1).

Conclusion The functional impact of anaesthetic on trans-sarcolemmal $\mathrm{Ca}^{2+}$ exchange (L-type $\mathrm{Ca}^{2+}$ current, $\mathrm{Na}^{+}-\mathrm{Ca}^{2+}$ exchange, $\mathrm{Ca}^{2+}$ ATPase export pump) is independent of the anaesthetic at equipotent concentrations, except for enflurane which had a larger effect.

Support: GM36365 and Mayo Foundation.

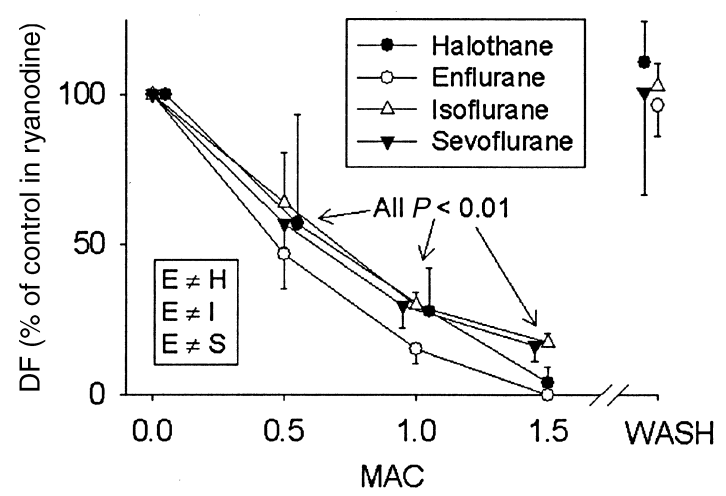

Fig. 1. Effects of four volatile anaesthetics on myocardial contractility.

ABSTRACT NO. 9

Ketamine blocks the cardioprotection by ischaemic preconditioning

W. Schlack*, J. Mullenheim* and V. Thamer $†$

*Institutes of Anaesthesiology and †Physiology, HeinrichHeine-University, Düsseldorf, Germany

Introduction Short-term ischaemia prior to prolonged 
ischaemia (ischaemic preconditioning $=\mathrm{IP}$ ), is the strongest endogenous cardioprotective mechanism. Opening of the ATP-sensitive potassium channel is the key mechanism of IP. In vitro, racemic ketamine (RK) can block this channel [1]. We investigated whether a clinical dose of RK or S-ketamine blocks the cardioprotection of IP in rabbits.

Methods Thirty-seven chloralose-anaesthetized rabbits underwent 30-min occlusion of a coronary artery and $2 \mathrm{~h}$ of subsequent reperfusion. The control group (CON, $n=10$ ) underwent the ischaemia-reperfusion programme without IP. In the preconditioning group (IP, $n=10$ ), IP was elicited prior to the 30 -min period of ischaemia by a 5-min period of ischaemia followed by $10 \mathrm{~min}$ of reperfusion. In the ketamine groups, RK (10 $\mathrm{mg} \mathrm{kg}^{-1}, n=9$ ) or SK (10 $\left.\mathrm{mg} \mathrm{kg}^{-1}, n=8\right)$ was given five minutes prior to the preconditioning ischaemia. Left ventricular peak systolic pressure (LVPSP, tip-manometer), cardiac output (CO, ultrasonic flow probe) and infarct size (triphenyltetrazolium staining) were determined. Statistical analysis was by ANOVA followed by Dunnett's post-test.

Results Data are mean values \pm SEM. Baseline values were similar in all groups (LVPSP: $107 \pm 2 \mathrm{mmHg}$, CO: $180 \pm 4 \mathrm{~mL} \mathrm{~min}^{-1}$ ). After IP, LVPSP and CO recovered during the 10-min reperfusion period to baseline values. During coronary occlusion, LVPSP and CO were reduced to the same extent in all groups (to 82 $\pm 2 \%$ and $84 \pm 1 \%$ ). After 2 -h reperfusion, functional recovery was similar in all groups (LVPSP: $74 \pm 3 \%$, CO: $85 \pm 3 \%$ ). The infarct size of the area of risk was greater in unpreconditioned controls $(45 \pm 5 \%)$ and RK-treated animals $(45 \pm 6 \%)$ than in SK-treated animals $(25 \pm 4 \%)$ and the IP-group $(24 \pm 5 \%, P<0.05$ vs. CON and RK).

Conclusion Ketamine blocks the cardioprotective effect of ischaemic preconditioning in vivo, but Sketamine does not. Thus, the influence of ketamine on IP is most likely isomer specific and S-ketamine may be preferable if there is a risk of myocardial ischaemia.

\section{Reference}

$1 \mathrm{Ko}$ SH, Lee S-K, Ham Y-J et al. Blockade of myocardial ATP-sensitive potassium channels by ketamine. Anesthesiology 1997; 87: 68-74.
ABSTRACT NO. 10

Inducible NO synthase (NOS2) - cyclo-oxygenases (COX) interactions in vivo implication for pharmacological inhibition of NOS2 activity

Y. Devaux, C. Seguin, N. de Talance, C. Burlet, F. Zannad, C. Meistelman, P.-M. Mertes and D. Longrois UPRESS 971068, Nancy I, France

Introduction NOS2 activation contributes to arterial hypotension of septic shock. Nevertheless, pharmacological inhibition of NOS2 activity results in vasoconstriction, decreased cardiac output and increased mortality through incompletely characterized mechanisms. Our hypothesis was that NOS2 pharmacological inhibition could alter other pathways modulating vasodilatation, such as the cyclo-oxygenase pathways.

Methods Wistar-Kyoto rats received $6 \mathrm{mg} \mathrm{kg}^{-1}$ lipopolysaccharide (LPS, i.p.) and 50 or $100 \mathrm{mg} \mathrm{kg}^{-1}$ aminoguanidine ( $A G$, i.p.) twice $(15 \mathrm{~min}$ before and $3 \mathrm{~h}$ after LPS). Rats were sacrificed $6 \mathrm{~h}$ after LPS injection. NOS2, COX-1 and COX-2 expression was studied by semiquantitative RT-PCR (mRNA) and Western blot (protein). Plasma nitrate/nitrite and 6-keto-PGF1 $\alpha$ concentrations were evaluated by the Griess reaction and ELISA, respectively.

Results LPS increased NOS2 expression and activity. LPS decreased COX-1 and modestly increased COX-2 expression but significantly increased global COX activity. AG dose-dependently inhibited NO production (plasma nitrate/nitrite); this was associated with decreased 6-keto-PGF1 $\alpha$ plasma concentration (Table 1).

Table 1. Effects of retinoic acid and LPS on the synthesis of cyclo-oxygenase and prostanoids

\begin{tabular}{lll}
\hline & $\begin{array}{l}\text { Nitrate/nitrite } \\
(\mu \mathrm{mol})\end{array}$ & $\begin{array}{l}\text { 6-keto-PGF1 } \alpha \\
\left(\mathrm{ng} \mathrm{mL}^{-1}\right)\end{array}$ \\
\hline Control & $2.50 \pm 0.14$ & $1.22 \pm 0.22$ \\
LPS & $5.28 \pm 0.409$ & $2.57 \pm 0.11 \dagger$ \\
LPS + AG $50 \mathrm{mg} \mathrm{kg}^{-1}$ & $3.46 \pm 0.26^{*} \dagger$ & $1.93 \pm 0.12^{*} \dagger$ \\
LPS + AG $100 \mathrm{mg} \mathrm{kg}^{-1}$ & $2.44 \pm 0.45^{*}$ & $1.62 \pm 0.08$ \\
\hline
\end{tabular}

Mean \pm SEM; $n=6$ in each group

${ }^{*} P<0.05$ vs. LPS; $\uparrow P<0.05$ vs. control. 
Conclusion These results suggest that pharmacological inhibition of NOS2 activity in vivo, by decreasing NO production, also attenuates NO-dependent COX enzymatic activity. They are in favour of an interaction between NOS2 pathway and COX activity in vivo that could explain, at least in part, the deleterious effects of NOS2 pharmacological inhibition.

\section{ABSTRACT NO. 11}

The safety of one, or repeated, vital capacity manoeuvres during general anaesthesia

L. Magnusson, H. Tydèn and G. Hedenstierna

University Hospital of Uppsala, Sweden

Introduction A vital capacity manoeuvre (VCM) (inflating the lungs to $40 \mathrm{cmH}_{2} \mathrm{O}$ for $15 \mathrm{~s}$ ) is effective in relieving atelectasis during general anaesthesia or after cardiopulmonary bypass (CPB). However, inflating the lungs to vital capacity carries potential negative effects such as barotrauma or haemodynamic depression. The study was undertaken to investigate the safety of one or repeated VCM, with or without CPB.

Methods Five groups of six pigs were studied. Two groups had general anaesthesia for $6 \mathrm{~h}$ with one group submitted to a VCM every hour. Three other groups received CPB. VCM was performed after the bypass in two of these groups. WM was then repeated every hour in one of the groups.

Lung damage was evaluated by extravascular lung water (EVLW) measurement, light microscopy and by the half-time of disappearance from the lung of a nebulized aerosol containing ${ }^{99 m} \mathrm{Tc}$-DTPA $\left(\mathrm{T}_{1 / 2}\right)$.

Results No changes were noted in EVLW. The pigs subjected to VCM decreased their $T_{1 / 2}$. In the groups exposed to repeated VCM, $\mathrm{T}_{1 / 2}$ remained low (CPB pigs) or decreased over time (non-CPB pigs). No lung damage was seen on the morphology study.

Conclusion These results suggest that one VCM is a safe procedure. The increase in lung clearance of ${ }^{99 m}$ Tc-DTPA seen with repeated VCM is best explained by an increase in lung volumes. Indeed, this increase was not associated with an increase in lung water and no alveolar disruption could be seen on the morphology study. Therefore, repeated VCM appears also to be a safe procedure.
ABSTRACT NO. 12

A comparison of two procedures for weaning patients from mechanical ventilation after cardiac surgery

P. Cavadore, M. Sebbane, F. Habib and P. Colson

University Hospital of Montpellier, France

Introduction Pressure support ventilation (PSV) is a common way of weaning patients after cardiac surgery but some subjective elements may delay the time of extubation [1]. We tried to optimize this method by using a weaning algorithm.

Methods During the first month, patients were weaned from mechanical ventilation as usual. PSV was set with an inspiratory assistance level (IAL) of $16 \mathrm{cmH}_{2} \mathrm{O}$ as the patient awoke. The level of assistance was then progressively reduced so long as the patient was able to breathe with a tidal volume of 6$8 \mathrm{~mL} \mathrm{~kg}^{-1}$ and a frequency between 10 and 20 cycles $\min ^{-1}$. When the patients reached IAL 8, they were extubated unless there was an excessive bleeding or haemodynamic instability. In the second month, we used an incremental algorithm (Inc). Patients were given PSV with an IAL of $8 \mathrm{cmH}_{2} \mathrm{O}$. If the patients fulfilled our extubation criteria, they were extubated after $30 \mathrm{~min}$ of spontaneous breathing. If they did not, another inspiratory assistance level was set to the lowest value required. After $30 \mathrm{~min}$ the patients were put again on IAL 8 and checked for extubation criteria. Patients with an acute or chronic respiratory disease were excluded.

We compared the length of mechanical ventilation between the two groups of patients. Statistical analysis was performed using Student's $t$-test; $P<0.01$ was considered significant.

Results One-hundred-and-fifteen patients undergoing CABG or valvular replacement were studied consecutively, 67 patients in the first group (Dec) and 48 patients in the second group (Inc). The two groups were similar in terms of age, ASA and NYHA dyspnoea scores, surgery and duration of aortic clamping. No patient had to be reintubated. The mean duration of ventilation was shorter in the Inc group than in the Dec group $(498 \pm 222$ vs. $684 \pm 246 \mathrm{~min}, P$ $<0.001$ ) whereas time to recover spontaneous breathing was similar in the two groups.

Conclusion We found that the use of pressure support ventilation with an incremental weaning algo- 
rithm can reduce the duration of intubation after cardiac surgery.

\section{Reference}

1 Fontes ML, Afifi MS, Sofair M, Schmaelzle A, Biondi JW, Hines RL. Is computer weaning from mechanical ventilation superior to clinician-directed weaning following cardiac surgery? Anesth Analg 1997; 84: SCA42.

ABSTRACT NO. 13

Effect of increased $\mathrm{FiO}_{2}$ before extubation on postoperative atelectasis

Z. Benoît, S. Wicky, J.-F. Fischer and L. Magnusson University Hospital, Lausanne, Switzerland

Introduction It has been shown that during induction of anaesthesia, the use of high $\mathrm{FiO}_{2}$ favours atelectasis formation. A vital capacity manoeuvre (VCM) (inflating the lungs to $40 \mathrm{cmH}_{2} \mathrm{O}$ for $15 \mathrm{~s}$ ) performed after intubation, virtually eliminates all atelectasis. It is a common practice to use $100 \% \mathrm{O}_{2}$, before extubation. It is not known to what extent this practice can favour postoperative atelectasis formation, when a VCM is not possible. The aim of this study was therefore to evaluate if maintaining a low $\mathrm{FiO}_{2}$ (0.4) until the end of general anaesthesia could prevent atelectasis formation.

Methods After written informed consent, 30 patients were randomly assigned to 1 of 3 groups. Randomization was performed $15 \mathrm{~min}$ before the end of operation. In two groups, a VCM was performed, thereafter $\mathrm{FiO}_{2}$ was increased to 1.0 in one group (VCM + 1.0), but was kept constant at 0.4 in the other group (VCM $+0.4)$. The third group served as control, $\mathrm{FiO}_{2}$ was increased to 1.0 without VCM. The amount of atelectatic lung tissue was measured by CT-scan performed after extubation at the level of the interventricular septum. Arterial blood gases were measured after the CT-scan.

Results There was no difference between the control and $\mathrm{VCM}+1.0$ groups in the amount of atelectasis or oxygenation (Table 1). The VCM +0.4 group showed significantly less atelectasis and better oxygenation when compared with control or the $\mathrm{VCM}+1.0$ group.
Table 1. Atelectasis related to $\mathrm{FiO}_{2}$ values

\begin{tabular}{lrcc}
\hline & Control & $\mathrm{VCM}+1.0$ & $\mathrm{VCM}+0.4$ \\
\hline Atelectasis & $8.5 \pm 6.2^{*}$ & $7.3 \pm 3.5^{* *}$ & $2.7 \pm 1.1$ \\
$\mathrm{PaO}_{2} / \mathrm{FiO}_{2}$ & $402.0 \pm 79.2$ & $359.2 \pm 46.2^{* *}$ & $458.0 \pm 49.3$ \\
\hline
\end{tabular}

${ }^{*} P<0.05$ and ${ }^{*} P<0.01$ compared with $\mathrm{VCM}+0.4$

Conclusion Maintaining a 'low' $\mathrm{FiO}_{2}$ until the end of general anaesthesia, associated with a VCM, avoids postoperative atelectasis formation at a time when a VCM is no longer possible.

ABSTRACT NO. 14

Early extubation in paediatric cardiac surgery using thoracic epidural anaesthesia with ropivacaine-morphine

E. Rodríguez, R. Vilà, T. Trull, V. Garrido and E. Miguel Hospital Universitari Materno-Infantil Vall d'Hebron, Autonomous University of Barcelona, Barcelona, Spain

Introduction Thoracic epidural anaesthesia (TEA) in paediatric patients is often used as part of an anaesthetic technique for aggressive thoracic surgery. The benefits in postoperative pain relief are associated with an improved outcome, related to postoperative pulmonary, cardiovascular immunological, and coagulation functions in high-risk surgical patients [1]. The use of epidural opioids for analgesia after cardiac surgery has also been hindered by concerns about anticoagulation and potential complications. Recent studies describe safe epidural catheterization in cardiac surgery.

Methods With the approval of the institutional review board and parental consent, we present a study about TEA in 10 patients between 2 and 13-year-old, 9-27 kg, eight with atrial defects (ASD) and two with ventricular septal defects (VSD). After standardized light general anaesthesia, TEA median approach $\mathrm{T}_{7}-$ $\mathrm{T}_{9}$ interspace in the left lateral decubitus position was performed using Tuohy G18 needles. The epidural space was identified by the loss of resistance to normal saline. We administered $0.5-0.75 \mathrm{~mL} \mathrm{~kg}^{-1}$ of $0.2 \%$ ropivacaine, according to age, associated with $50 \mu \mathrm{g}$ 
$\mathrm{kg}^{-1}$ morphine. Maintenance was with ropivacaine $0.2 \%$ at $0.2 \mathrm{~mL} \mathrm{~kg}^{-1} \mathrm{~h}^{-1}$, atracurium $0.5 \mathrm{mg} \mathrm{kg}^{-1}$, sevoflurane $1 \%$ and midazolam $0.3 \mathrm{mg} \mathrm{kg}^{-1}$ during cardiopulmonary bypass (CPB). Five blood samples were obtained at different times to measure the concentrations of stress hormones. Postoperative epidural analgesia was provided by $30 \mu \mathrm{g} \mathrm{kg}^{-1}$ morphine per 12-18 h.

Results All patients were extubated in the operating room. In the postoperative period four patients (40\%) needed a second dose of morphine. The analgesia obtained was satisfactory in $100 \%$ of cases and no other analgesics were used. The catecholamine response, reflected by epinephrine and norepinephrine release during sternotomy, was abolished. However, TEA was insufficient to prevent all the hormonal changes during CPB. No major complications occurred.

Conclusion When the procedure is performed by experts in epidural anaesthesia and the correct patients are chosen, the results are excellent. Early tracheal extubation, haemodynamic stability, prolonged postoperative analgesia, and improved respiratory function are advantages of TEA in cardiac surgery.

\section{Reference}

1 Liu S, Carpenter R, Neal JM. Epidural anesthesia and analgesia. Their role in postoperative outcome. Anesthesiology 1995; 82: 1474-1506.

ABSTRACT NO. 15

Effects of PEEP on quasi-static respiratory compliance and arterial oxygenation in morbidly obese patients undergoing laparoscopic gastric banding

A. Vannucci, F. Vagginelli, S. Francesconi, A. Tiby, F. Valenza, G. Ronzoni and L. Gattinoni

Ist. di Anestesia e Rianimazione, Osp. Maggiore di MilanoIRCCS, ITALIA

Introduction The aim of this study was: (a) to evaluate in morbidly obese patients the variation of quasi- static respiratory compliance (RC) and $\mathrm{PaO}_{2} / \mathrm{FiO}_{2}$ induced by pneumoperitoneum (PNP) and surgical positioning (beach chair position) and (b) to assess the effects of three levels of PEEP (ZEEP, $5 \mathrm{~cm} \mathrm{H}_{2} \mathrm{O}$ PEEP, $10 \mathrm{cmH}_{2} \mathrm{O}$ PEEP) on $\mathrm{RC}$ and $\mathrm{PaO}_{2} / \mathrm{FiO}_{2}$ during laparoscopic gastric banding.

Methods Fourteen morbidly obese patients (13 women), BMI $43.5( \pm 8.4) \mathrm{kg} \mathrm{m}^{-2}$, age $39( \pm 10.2)$ year, were randomized into three groups $(A, B, Z)$. Mechanical ventilation was set as follows: IPPV mode, TV 12 $\mathrm{mL} \mathrm{kg} \mathrm{kg}^{-1}$ ideal body weight, respiratory rate 10 breaths $\min ^{-1}, \mathrm{Ti} 33 \%$, no inspiratory pause, $\mathrm{FiO}_{2}$ $60 \%$. PEEP strategy differed between groups: group $\mathrm{A}$ was tested first, with a 5 and then $10 \mathrm{cmH}_{2} \mathrm{O}$ PEEP: in group $\mathrm{B}$ vice versa, while group $\mathrm{Z}$ always received ZEEP. Four measurement of $\mathrm{RC}$ and $\mathrm{PaO}_{2} / \mathrm{FiO}_{2}$ ratio were made: (a) after induction of anaesthesia and pulmonary recruitment manoeuvre; (b) after PNP insufflation and recruitment manoeuvre, (c) surgical positioning; and (d) during the surgical procedure.

Results PNP and surgical positioning resulted in a reduction in $\mathrm{RC}$ but no variation in $\mathrm{PaO}_{2} / \mathrm{FiO}_{2}$. In groups $A$ and $B$ the application of PEEP significantly improved $\mathrm{RC}(P<0.05)$, the higher $\mathrm{RC}$ was observed with $10 \mathrm{cmH}_{2} \mathrm{O}$ PEEP; in group $\mathrm{Z} \mathrm{RC}$ remained significantly lower. Also $\mathrm{PaO}_{2} / \mathrm{FiO}_{2}$ ratio improved significantly $(P=0.05)$ in groups $A$ and $B$ with $10 \mathrm{cmH}_{2} \mathrm{O}$ PEEP, but never changed in group $Z$ (Fig 1).

Conclusion PEEP improved $\mathrm{RC}$ and $\mathrm{PaO}_{2} / \mathrm{FiO}_{2}$ ratio in this population of morbidly obese patients.

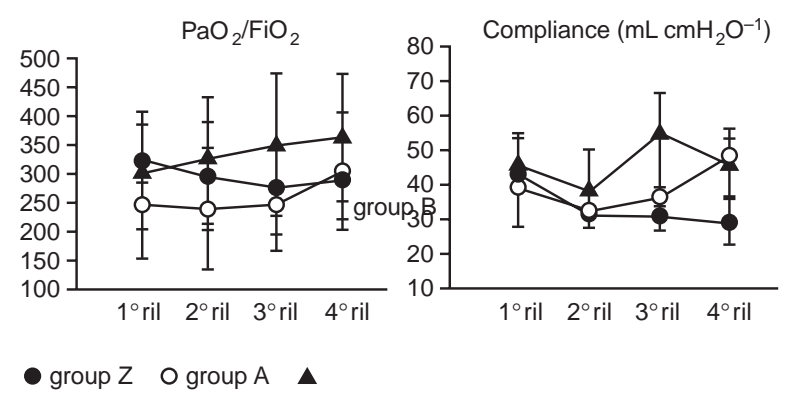

Fig. 1. $\mathrm{PO}_{2} / \mathrm{FiO}_{2}$ ratio and compliance during the four investigative periods. 


\section{ABSTRACT NO. 16}

Volume controlled high-frequency oscillatory ventilation and haemodynamic changes in adults

J. Pachl*, K. Roubík†, V. Zábrodský*, J. Krejzl* and B. Bakaláŕ ${ }^{*}$

*Department of Anaesthesiology and CCM, Charles University, 3rd School of Medicine, Srobdrova 50, Prague 10, and $\uparrow$ Department of Radioelectronics, FEE CTU, Prague, Czech Republic

Introduction The aim of the study was to evaluate the suitability of volume controlled high-frequency oscillatory ventilation (HFOV) in adults using a special measuring and monitoring system.

Methods A special monitoring and evaluation system for HFOV has been designed, which is able to measure tidal volume (VT) and other parameters. A special algorithm [1] has been developed for evaluation of alveolar pressure and the respiratory system parameters, based on mathematical modelling. Patients with ARDS and $\mathrm{PaO}_{2} / \mathrm{FiO}_{2}<200$ were included (5 data sets) into the study. First, HFOV (SensorMedics 310013) was started at $5 \mathrm{~Hz}$, with MAP $0.5 \mathrm{kPa}$ above previous MAP during conventional ventilation (Power 4, Bias $40 \mathrm{~L} \mathrm{~s}^{-1}$ ) and $T_{\text {insp }} / T_{\text {exsp }}=0.5$. Amplitude (AP) was set according to the recommendation (as well as other parameters) based on experience such that the thorax performed sufficient oscillations. Normocapnia was not reached. Then the ventilation mode was changed to volume controlled HFOV. Power and AP had to be changed to achieve normocapnia. Blood gas analysis was used to verify the two approaches. Haemodynamic parameters such as CO, PCWP, CVP, PAP, SV, SVR and PVR were continuously monitored. The following ventilation parameters were also measured: airway pressure, airflow, $\mathrm{V}_{\mathrm{T}}, \mathrm{PIP}, \mathrm{MAP}, \mathrm{PEEP}$, $\mathrm{PIP}_{\mathrm{alv}}, \mathrm{PEEP} \mathrm{Plv}_{\mathrm{v}}, \mathrm{MV}, \mathrm{C}_{\mathrm{L}}$ and $\mathrm{R}_{\mathrm{AW}}$.

Results Normocapnia was reached in the second case only, with the maximal power, VT about $400 \mathrm{~mL}$ (3.8$5.0 \mathrm{~mL} \mathrm{~kg}^{-1}$ ), airflow $5 \mathrm{~L} \mathrm{~s}^{-1}$ and $\mathrm{MV}=130 \mathrm{~L} \mathrm{~min}^{-1}$. Values of the first (recommended) setting were: VT about $250 \mathrm{~mL}\left(2.4-3.1 \mathrm{~mL} \mathrm{~kg}^{-1}\right)$, airflow $2.8 \mathrm{~L} \mathrm{~s}^{-1}$ and $\mathrm{MV}=80 \mathrm{~L} \mathrm{~min}^{-1}$. Maximal power was used. Haemodynamic profiles showed a reasonable increase in both SVR and arterial pressure in the normoventilation period and in the time of improved oxygenation.

Conclusion Results confirm the suitability of the HFOV monitoring system for adults and necessity of tidal volume monitoring as well in comparison with an incorrect empirical approach. The resistive systemic response during HFOV is very significant. A special interest is given to this in the current study.

\section{Reference}

1 Roubile $\mathrm{K}$ et al. Real time monitoring and evaluation system for high frequency ventilation. In: Proceedings of the 8th IMEKO Conference. Dubrovnik: KoREMA, 1998, pp. 19-22(ISBN 953-6037-26-2).

Supported by GA CR 305/00/065 1, IGA MSMT CR VS97033, VZ:J04198: 210000012 and VZ:J13198: 111200003.

\section{ABSTRACT NO. 17}

\section{Epidural vs. continuous intercostal block following thoracotomy}

G. Debreceni, L. Szélig, T. F. Molnár and ZS. Molnár Medical University of Pécs, Hungary

Introduction Although satisfactory pain relief is mandatory following thoracotomy in order to prevent postoperative pulmonary complications, there is controversy regarding the techniques in current use [1]. Our aim was to compare the effects of continuous thoracic epidural (EDA) vs. continuous intercostal (IC) blocks on pain relief and pulmonary function.

Methods In a prospective, randomized controlled study, 49 patients scheduled for pulmonary lobectomy were recruited. Twenty-seven patients received EDA $10.25 \%$ bupivacaine $0.2 \mathrm{~mL} \mathrm{~kg}^{-1}$ bolus followed by $5-10 \mathrm{~mL} \mathrm{~h}^{-1}$ infusion), performed by the same anaesthetist and 22 received IC analgesia $0.5 \%$ bupivacaine $20 \mathrm{~mL}$, followed by continuous infusion of bupivacaine $0.25 \% 5-10 \mathrm{mLh}^{-1}$ ), performed intraoperatively by the same surgeon. Pain relief was assessed using a visual analogue scale (VAS: 0-10) 4 hourly for $20 \mathrm{~h}$. If VAS $>4,100 \mu \mathrm{g}$ fentanyl was given i.v. Pulmonary function tests (PFT): FVC, PEFR, $\mathrm{FEF}_{25-75}, \mathrm{FEV}_{1} / \mathrm{FVC}$ were obtained before, and 4, $24 \mathrm{~h}$ after the operation. One-way ANOVA was used to test for significance.

Results There was no difference between the groups in age, gender, operating time, intraoperative fentanyl requirements, and preoperative PFTs. The VAS1 (mean \pm SD) was $53 \pm 3.3$ vs. $7.1 \pm 2.1, P=0.03$, the 
VAS2 was $(3.6 \pm 1.9$ vs. $5.5 \pm 2.7, P=0.007)$, the VAS3 was $(3.1 \pm 1.8$ vs. $5.1 \pm 2.5, P=0.002)$; scores were significantly higher in the IC group. There were no significant differences between the two groups with respect to further VAS, respiratory, haemodynamic parameters and PFTs. Although the fentanyl requirement was higher in the IC group $(350 \pm 277 \mu \mathrm{g}$ vs. 502 $\pm 297 \mu \mathrm{g}$ ) it did not reach statistical significance.

Conclusion EDA was superior in the first 12 postoperative hours according to VAS. Statistically significant differences could not be shown for the rest of the variables studied.

\section{Reference}

1 Conacher ID. Pain relief after thoracotomy. $\mathrm{Br} J$ Anaesth 1990; 65: 806-812.

\section{ABSTRACT NO. 18}

Intravesical pressure reflects intra-abdominal pressure whatever the cause of raised intra-abdominal pressure (pneumoperitoneum or liquid effusion)

P. Diemunsch, R. Schaeffer, A. Launoy, I. Badu and J. Leroy

University Hospital of Strasbourg, France

Introduction Pathophysiological consequences of the abdominal compartment syndrome are similar to those observed with pneumoperitoneum during laparoscopic surgery. The aim of this study was to compare intravesical pressure (IVP) measured with a transurethral catheter (Foley tube - $I V P_{F}$ ) or a cystocatheter $\left(I V P_{C}\right)$, during increase of intra-abdominal pressure (LAP) by $\mathrm{CO}_{2}$ insufflation or liquid inflation.

Methods Eight large white pigs (weighing 30-35 kg) were anaesthetized (ketamine, azaperone, thiopental, pancuronium) and ventilated via an endotracheal tube $\left(\mathrm{O}_{2} / \mathrm{N}_{2} \mathrm{O}\right.$ : $50-50 \%, \mathrm{~F}_{\mathrm{ET}}$ isoflurane $1.5 \mathrm{vol} \%$, Dräger, Cicero). They had a transurethral tube, a cystocatheter and an intra-abdominal catheter for direct IAP measurements. $\mathrm{CO}_{2}$ and liquid were administered by a separate tube. Position of the catheters was controlled by laparoscopy. IAP was increased from 0 to 10 and $15 \mathrm{mmHg}$ with $\mathrm{CO}_{2}$ insufflation. After return to baseline $(0 \mathrm{mmHg})$, IAP was increased with liquid inflation (saline). $I V P_{F}$ and $I V P_{C}$ were measured for each step of IAP; the bladder containing $100 \mathrm{~mL}$ sal- ine. Relations between $I V P_{F}$ and IAP, IVP $P_{C}$ and IAP, $I V P_{F}$ and $I V P_{C}$ were analysed using linear regression test, for $\mathrm{CO}_{2}$ insufflation $\left(\mathrm{IAP}_{\text {gas }}\right)$ and liquid inflation $\left(\mathrm{IAP}_{\text {saline }}\right)$. IVP measurements during gas insufflation $\left(\mathrm{IVP}_{\text {gas }}\right)$ and liquid inflation $\left(\right.$ IVP $\left._{\text {saline }}\right)$ were compared using ANOVA analysis.

Results $\mathrm{CO}_{2}$ insufflation:

$\operatorname{IVP}_{\mathrm{F}}=6+0.59 \mathrm{IAP}_{\mathrm{gas}} \quad\left(\mathrm{R}^{2}=0.656\right)$

$I_{\mathrm{IVP}}=5.1+0.66 \mathrm{IAP}_{\mathrm{gas}}\left(\mathrm{R}^{2}=0.808\right)$

$\operatorname{IVP}_{\mathrm{F}}=0.96 \mathrm{IVP}_{\mathrm{C}} \quad\left(\mathrm{R}^{2}=0.971\right)$

Saline inflation:

$\mathrm{IVP}_{\mathrm{F}}=5.65+0.77 \mathrm{IAP}_{\text {saline }}\left(\mathrm{R}^{2}=0.891\right)$

$\operatorname{IVP}_{\mathrm{C}}=3.7+0.80 \mathrm{IAP}_{\text {saline }}\left(\mathrm{R}^{2}=0.803\right)$

$\operatorname{IVP}_{\mathrm{F}}=1.03 \mathrm{IVP}_{\mathrm{C}} \quad\left(\mathrm{R}^{2}=0.978\right)$

IVP values during gas insufflation were not different from those during liquid inflation $(P=0.36)$; $\mathrm{IVP}_{\text {saline }}=-1.401+1.166 \mathrm{IVP}_{\text {gas }}\left(\mathrm{R}^{2}=0.768\right)$.

Conclusion IAP, IVP $F$ and IVP $\mathrm{P}_{\mathrm{C}}$ are well correlated whether IAP is increased by gas or liquid. Intraabdominal liquid effusion increases LAP as does a pneumoperitoneum.

\section{ABSTRACT NO. 19}

Gastrointestinal perfusion during severe sepsis without shock: effect of dobutamine

G. Lebuffe, J. Leclerc, B. Levy, R. Nevière, J. L. Chagnon, J. L. Teboul, P. F. Perrigault, A. Edouard, J. Duranteau, E. Haddad and B. Vallet

Groupe de Recherche sur I'Oxygenation Tissulaire, DAR 2, $\mathrm{CHU}$, Lille, France

Introduction Dobutamine is known to improve gastrointestinal perfusion in patients with septic shock. The aim of this study was to appreciate the effect of an early dobutamine infusion on gastrointestinal perfusion in patients with severe sepsis.

Methods After Ethical Committee approval and informed consent, patients with severe sepsis were included according to ACCM/SCCP criteria. A gastric tonometer (TRIP ${ }^{\mathbb{R}}$ ) connected to an automated gas analyser (TONOCAP $\left.{ }^{(i i}\right)$ was inserted. Patients were divided into two groups according to gastric-to-arterial $\mathrm{CO}_{2}$ gap $\left(\Delta \mathrm{CO}_{2}\right)$ [Group I, $\Delta \mathrm{CO}_{2} \leq 8 \mathrm{mmHg}$; Group 2, $\Delta \mathrm{CO}_{2}>8 \mathrm{mmHg}$. Each group was then randomized to receive either dobutamine $\left(5 \mu \mathrm{g} \mathrm{kg}^{-1} \mathrm{~min}^{-1}\right)$ or saline over $72 \mathrm{~h}$. Haemodynamics, lactate and tonometric variables were measured at $\mathrm{H} 0, \mathrm{H} 2, \mathrm{H} 6$, 
$\mathrm{H} 12, \mathrm{H} 24, \mathrm{H} 48, \mathrm{H} 72$. Data (mean $\pm \mathrm{SD}$ ) were analysed using Mann-Whitney test (Group I vs. Group 2) and Friedman test ( $\mathrm{HO}$ vs. $\mathrm{Hx}$ ). Receiver operating characteristic (ROC) curves were used to assess prognostic value of $\Delta \mathrm{CO}_{2}$ at $\mathrm{HO}$.

Results Forty-two patients (age $61.0 \pm 13.3$ years) were included (Group I: $n=17$; Group 2: $n=25$ ). SAPS II was similar in both groups (Group I: $45.0 \pm$ 16.5 vs. Group 2: $43.8 \pm 16.2$ ). At $\mathrm{HO}, \Delta \mathrm{CO}_{2}$ was significantly higher in Group $1(4.0 \pm 2.6 \mathrm{mmHg})$ than in Group $2(14.7 \pm 6.2 \mathrm{mmHg}, P<0.05)$ while mean arterial pressure (Group I: $89.1 \pm 20.1$ vs. Group 2:77.5 \pm $15.9 \mathrm{mmHg}$ ) and blood lactate (Group I: $1.8 \pm 1.2$ vs. Group 2: $1.8 \pm 1.2 \mathrm{mM} \mathrm{L}^{-1}$ ) were not different between the two groups. Dobutamine infusion did not significantly change the haemodynamics, blood lactate concentration or tonometric parameters in any group within the first $72 \mathrm{~h}$ (Fig. 1). Mortality was $29 \%$ in Group 1 and $36 \%$ in Group 2. $\Delta \mathrm{CO}_{2}$ had no prognostic value of mortality in septic patients without shock.

Conclusion An early infusion of dobutamine during the first $72 \mathrm{~h}$ of severe sepsis without shock does not influence gastric $\Delta \mathrm{CO}_{2}$; this suggest that $5 \mu \mathrm{g} \mathrm{kg}^{-1}$ $\mathrm{min}^{-1}$ of dobutamine would not alter gastrointestinal blood flow in this population.

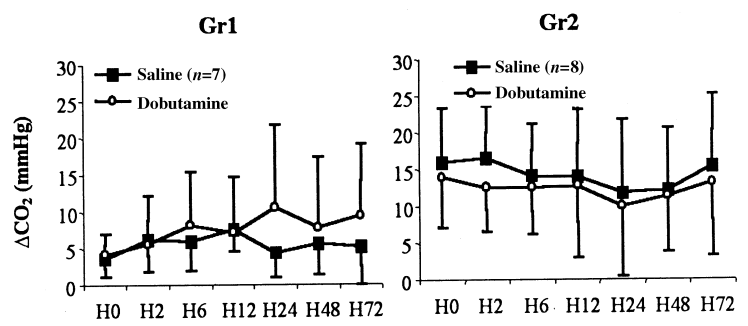

Fig. 1. Influence of dobutamine on gastric $\Delta \mathrm{CO}_{2}$ tensions.
ABSTRACT NO. 20

Retinoic acid modulates cyclo-oxygenase expression and activity in LPS-stimulated rats in vivo

Y. Devaux, C. Seguin, N. de Talance, C. Burlet, F. Zannad, C. Meistelman, P.-M. Mertes and D. Longrois UPRESS 971068, Nancy 1, France

Introduction Vitamin A and its active metabolite retinoic acid (RA) have complex immunomodulatory properties and increase survival in several infectious diseases through poorly documented mechanisms. Our hypothesis was that the effects of RA could be related to its capacity to modulate cyclo-oxygenase (COX) expression and prostanoids synthesis, strong modulators of immune responses.

Methods Wistar-Kyoto rats received all-trans RA (10 $\mathrm{mg} \mathrm{kg}^{-1}$, i.p.) or vehicle daily for 5 days followed by LPS (4 $\mathrm{mg} \mathrm{kg}^{-1}$, i.p.) or saline and were sacrificed six hours later. COX-1 and COX-2 activation was studied for liver mRNA expression (RT-PCR) and plasma prostanoids accumulation (ELISA).

Results RA modestly changed COX-1 and COX-2 mRNA expression when administered alone or in addition to LPS. Global COX activity was highly increased by RA alone. The effects of RA and LPS were synergistic (Table 1).

Conclusion The highly increased COX activity observed in rats that received RA and/or lipopolysaccharide (LPS) cannot be explained by the moderately increased COX-2 expression. Several potential mechanisms are currently under investigation. These results may contribute to the understanding of the mechanisms through which RA modulates the immune function and host survival when challenged with different pathogens.

Table 1. Effects of RA and LPS on cyclo-oxygenase expression and prostanoids synthases

\begin{tabular}{|c|c|c|c|c|}
\hline & $\mathrm{RA}+\mathrm{LPS}$ & LPS & RA & Control \\
\hline COX-1 mRNA (AU) & $0.83 \pm 0.1 \uparrow \S$ & $0.92 \pm 0.1 \dagger \S$ & $1.94 \pm 0.1$ & $1.67 \pm 0.1$ \\
\hline COX-2 mRNA (AU) & $1.19 \pm 0.1^{*} \uparrow \S$ & $0.98 \pm 0.5 \S$ & $0.99 \pm 0.1 \S$ & ND \\
\hline 6-keto-PGF1 $\alpha\left(\mathrm{ng} \mathrm{mL}^{-1}\right)$ & $50.4 \pm 7.3^{*}+\S$ & $9.2 \pm 1.8 \S$ & $6.8 \pm 0.1 \S$ & $1.3 \pm 0.1$ \\
\hline $\mathrm{PGE}_{2}\left(\mathrm{ng} \mathrm{mL}^{-1}\right.$ ) & $825 \pm 64 * \dagger \S$ & $62 \pm 8 \S$ & $40 \pm 11 \S$ & $2 \pm 1$ \\
\hline $\mathrm{TxB}_{2}\left(\mathrm{ng} \mathrm{mL} \mathrm{m}^{-1}\right)$ & $5.4 \pm 0.6^{*} \uparrow \S$ & $2.2 \pm 0.7 \S$ & $1.6 \pm 0.8 \S$ & $0.9 \pm 0.2$ \\
\hline
\end{tabular}

Values are mean $\pm \mathrm{SEM} . \mathrm{AU}$ : arbitary units of densitometric analysis in liver. ND $=$ not detectable; ${ }^{*}, \dagger, \S$ vs. LPS, RA, and Control group, respectively.

(C) 2000 European Academy of Anaesthesiology, European Journal of Anaesthesiology, 17, 754-785 


\section{ABSTRACT NO. 21}

Latex allergy in subjects with bladder extrophy: relation with multiple surgical procedures and atopy

A. Gentili*, G. Ricci†, F. Di Lorenzot, A. Pigna*, M. Fae* and S. Baroncini*

*Department of Pediatric Anaesthesia, $\uparrow$ Pediatrics, $₫$ Pediatric Surgery, University of Bologna, Italy

Introduction Latex allergy is a medical problem that is progressively increasing. Children with urogenital malformations are more likely to have allergic reactions ranging from urticaria to anaphylaxis [1].

Methods We studied the prevalence of latex sensitisation in 19 children with bladder extrophy and the role of the associated risk factors such as atopy, surgical and anaesthetic procedures. Skin-prick tests and specific IgE assays against latex, food allergens cross-reacting with latex, and inhalant allergens were carried out.

Results Twelve patients (63\%) showed latex sensitization and five patients (26\%) showed symptoms related to latex. To analyse the influence of risk factors we divided the patients into three subgroups: latex symptomatic $(n=5)$, asymptomatic but latex sensitized $(n=7)$ and nonallergic nonsensitized $(n=7)$ (Table 1).

Latex symptomatic patients showed an increased inhalants and food allergens positivity. Symptomatic

Table 1. Risk factors

\begin{tabular}{lccc}
\hline & $\begin{array}{l}\text { Latex } \\
\text { sympto- } \\
\text { matic }\end{array}$ & $\begin{array}{l}\text { Latex } \\
\text { sensitized }\end{array}$ & $\begin{array}{l}\text { Latex } \\
\text { insen- } \\
\text { sitive }\end{array}$ \\
Risk factor & $4 / 5(80 \%)$ & $3 / 7(42 \%)$ & $1 / 7(14 \%)$ \\
\hline Inhalants, allergens & $4 / 5(80 \%)$ & $2 / 7(28 \%)$ & $0 / 7(0 \%)$ \\
Food allergens & $7.8 \pm 2.2$ & $6.8 \pm 3.2$ & $4.8 \pm 2.1 *$ \\
Operations ( $n$ ) & $39.4 \pm 6.6$ & $31.1 \pm 14.4$ & $19.7 \pm 7 \S$ \\
Length of operation & & & \\
$\quad$ (h) & $1.4 \pm 1.1$ & $1 \pm 1.1$ & $0.4 \pm 0.5$ \\
Intensive care & & & \\
$\quad$ hospitalization (days) & $4.8 \pm 5$ & $3 \pm 3.7$ & $5 \pm 6.3$ \\
Intensive care & & & \\
$\quad$ (days) & $5.6 \pm 2.8$ & $4.2 \pm 5.5$ & $0.4 \pm 1.1 \S$ \\
Catheterization (yr) & $4.8 \pm 1.3$ & $3 \pm 2.8$ & $2.1 \pm 1.3 \dagger$ \\
Cystographies $(n)$ & $2.2 \pm 0.4$ & $2 \pm 0.1$ & $1.8 \pm 0.3$ \\
Penrose drainage $n$ & & & \\
Penrose drainage (days) & $22.8 \pm 30.8$ & $7 \pm 7.2$ & $4.7 \pm 1.2$ \\
\hline
\end{tabular}

${ }^{*} P<0.03, \S P<0.001, \uparrow P<0.005$. patients had undergone a higher number of operations $(P<0.03)$, longer operations $(P<0.001)$, intensive care hospitalization, cystographic assessments $(P<0.005)$, a higher number and more days of Penrose drainage together with years of intermittent catheterization $(P<0.001)$.

Conclusion Multiple surgical and anaesthetic procedures and atopy play a major role in the development of latex hypersensitivity and latex allergy.

\section{Reference}

1 Turjanmaa K. Natural rubber latex allergy. Allergy 1996; 51: 593-602.

\section{ABSTRACT NO. 22}

Modulation of plasma viscosity by different colloids and its effect on supra-aortal blood flow in an animal model

M. Gro $\beta$ herr*, E. G. Kraatz*, M. Misfeld*, T. Gerrits $\dagger$ and K. F. Klotz*

*University Hospital of Lübeck and †University Hospital of Gießen, Germany

Introduction Previous study [1] has shown effects of various plasma substitutes on colloid osmotic pressure. This study is designed to evaluate modulation of plasma viscosity by different colloids and consequences on supra-aortal blood flow.

Methods Twenty-two healthy female domestic pigs were anaesthetized by $0.8 \%$ isoflurane and a continous i.v. infusion of ketamine and pancuronium. Haematological, rheological and blood flow variables were determined before (X1) and after (X2) gelatine (GEL) $4 \%$ (group $A, n=12$ ) or hydroxyethyl starch (HES) $10 \%$ 200/0.5 (group $B, n=10$ ) were infused i.v. with the amount of $30 \mathrm{~mL} \mathrm{~kg}^{-1}$ body weight over a period of $30 \mathrm{~min}$ in each group. The following parameters were measured: haematocrit (HC), plasma viscosity (PV), systolic (BFS) and diastolic (BFD) blood flow in the arteria centralis retinae. Statistical analysis was performed with the paired and unpaired Student's $t$-test, assuming $P<0.05$ as significant.

Results HC decreased significantly in each group between point $X 1$ and $X 2$ as a sign of haemodilution, but there was no difference between group $A$ and $B$. PV did not change within the groups or between the groups at point $X 1$, but PV was $6 \%$ signifantly lower 
for GEL at point X2. BFS increased for group A (+ $18 \%)$ and $B(+35 \%)$ significantly, while there was a significant increase in BFD only for group $A(+13 \%)$. Group $A$ and $B$ had a significant $15 \%$ higher BFD than group $B$ at point $X 2$.

Conclusion Comparing the effects of the infusion of GEL vs. HES ( $30 \mathrm{~mL} \mathrm{~kg}^{-1}$ body weight) a significant decrease in plasma viscosity for GEL is associated with a significant higher BFD [1].

\section{Reference}

1 Linko K, Makelainen A. Hydroxy ethyl starch 120, dextran 70 and acetated Ringer solution: hemodilution, albumin, colloid osmotic pressure and fluid balance following replacement of blood loss in pigs. Acta Anaesthesiologica Scand 1988; 32: 228-233.

\section{ABSTRACT NO. 23}

\section{Glutathione concentration during reperfusion after global ischaemia}

T. lijima, H. Sakamoto, T. Tatara and Y. Iwao

Department of Anesthesiology, Kyorin University of School of Med., Mitaka-City, Tokyo, Japan

Introduction Neuronal damage after incidental circulatory arrest is one of the crucial problems for anaesthesiologists. Glutathione is a sulfhydryl buffer for oxidative stress and seems to play an important role to prevent neuronal damage after ischaemic insult. We developed a quantitative method to estimate reduced (GSH) and oxidized form (GSSG) of glutathione in microdialysate in experimental ischaemic model.

Method Wistar rats $(n=8)$ were anaesthetised with isoflurane. Global ischaemia was induced by ligation of both carotid arteries and hypotension maintained for $25 \mathrm{~min}$, then the brain was reperfused for $120 \mathrm{~min}$. A microdialysis probe was implanted in the cortex and Ringer's solution was perfused at a rate of $2 \mathrm{~L}$ $\min ^{-1}$. Dialysate was analysed by using high performance liquid chromatography and reduced and oxidized glutathione was quantified.

Results GSH increased after ischaemia and reduced to control level in $120 \mathrm{~min}$. GSSG also increased 25 min after ischaemia and decreased to control level in 120 min (Fig. 1).

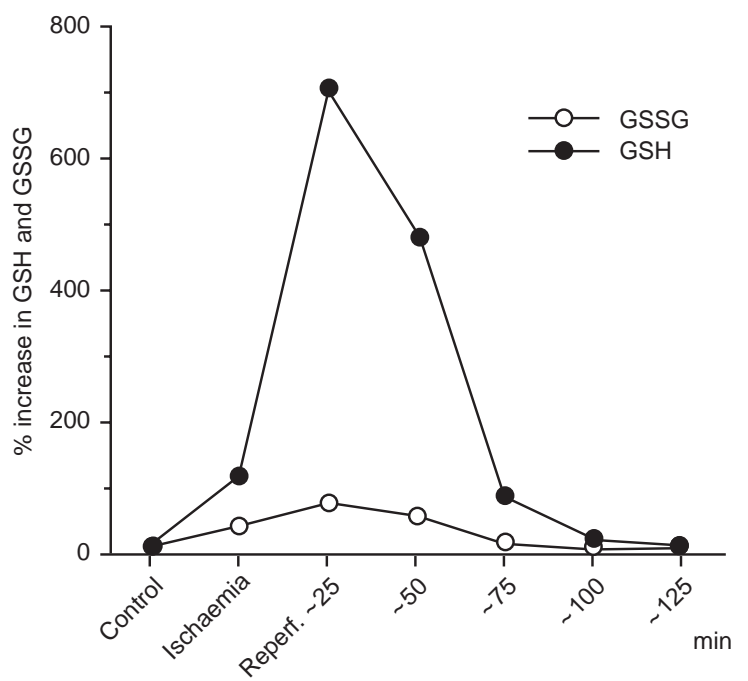

Fig. 1. Reduced and oxygenated glutathione concentrations following reperfusion after cerebral ischaemia.

Conclusion GSH rapidly appeared immediately after ischaemia and gradually decreased in $60 \mathrm{~min}$. GSH seems to be rapidly oxidised by free radicals produced during initial phase of reperfusion. This rapid change for only approximately $60 \mathrm{~min}$ is in accordance with the short therapeutic window after global ischaemia.

\section{ABSTRACT NO. 24}

Could we improve abdominal surgery with gastric tonometry?

J. Kopić

General Hospital, Slavonski Brod, Croatia

Introduction Maintenance of adequate splanchnic perfusion during the perioperative period is crucial for postoperative recovery. Even unmarked hypovolaemia could cause splanchnic hypoperfusion, with postoperative organ dysfunction [1]. The goal of our study was to determine whether splanchnic perfusion is disturbed in high-risk patients, during and after major abdominal operations.

Methods Twenty high-risk surgical patients were monitored with gastric tonometry. The TONOCAP (Tonometrics) was connected to a TRIP nasogastric 
catheter with an air-filled balloon. $\mathrm{pHi}$ is calculated using the tonometer from $\mathrm{prCO}_{2}, \mathrm{paCO}_{2}$ and $\mathrm{pHa}$. Measurements were performed every hour during operation and in the 2nd, 6th and 24th hours postoperatively. Data were statistically analysed as mean \pm SD.

Results Gastric acidosis $(\mathrm{pHi}<7.32$ ) was observed in $14.3-30 \%$ of patients during the monitored period. There was a trend to lower $\mathrm{pHi}$ values after the $2 \mathrm{nd}$ intraoperative hour and in the 2 nd and 6th postoperative hours (Table 1). In the last measurement the $\mathrm{pHi}$ was elevated.

Conclusion Our patients had episodes of gastric acidosis, during and immediately after operation. These results indicate disturbed splanchnic perfusion in some patients perioperatively. Closer monitoring of high-risk surgical patients, during and after major abdominal operations with gastric tonometry could be beneficial.

Table 1. Gastric acidosis in the perioperative period

\begin{tabular}{lllll}
\hline & $n$ & Minimum & Maximum & $\mathrm{x} \pm \mathrm{SD}$ \\
\hline $\mathrm{pH} 1$ & 20 & 7.19 & 7.60 & $7.44 \pm 012$ \\
$\mathrm{pH} 2$ & 20 & 7.13 & 7.56 & $7.36 \pm 0.12$ \\
$\mathrm{pH} 3$ & 14 & 7.14 & 7.43 & $7.36 \pm 0.07$ \\
$\mathrm{pH} 4$ & 7 & 7.11 & 7.38 & $7.31 \pm 0.09$ \\
$\mathrm{PH} 5$ & 20 & 7.08 & 7.53 & $7.35 \pm 0.11$ \\
$\mathrm{pH} 6$ & 20 & 7.18 & 7.56 & $7.36 \pm 0.09$ \\
$\mathrm{pH} 7$ & 20 & 7.10 & 7.59 & $7.38 \pm 0.10$ \\
\hline
\end{tabular}

\section{Reference}

1 Knichwitz G, Rotker J, Mollhof T et al. Continuous intramucosal $\mathrm{PCO}_{2}$ measurement allows the early detection of intestinal malperfusion. Crit Care Med 1998; 26: 15501557.

\section{ABSTRACT NO. 25}

Interrupted small-volume veno-venous haemofiltration in patients with peritonitis and acute respiratory failure

V. Obuhov, M. Petrova and S. Nikolaev

Hospital of Smolensk Medical Academy, Russian Federation
Introduction Haemofiltration is one of the important therapeutical components of patients with peritonitis and acute respiratory failure (ARF). With the aim to reduce some harmful effects of prolonged continuous extracorporeal circulation that is associated with activation of complement system and polymorphoneutrophils (PMNs) in these patients, the system of interrupted small-volume veno-venous haemofiltration (ISVVVH) was applied [1]. The object of our study was to investigate what influence ISVVVH may have on pulmonary gas exchange in patients with peritonitis and ARF.

Methods Seventy-two patients aged 26-58years were tested. A HR-77 'GAMBRO' filter was used with removal of $6-10 \mathrm{~L}$ of ultrafiltrate (average $7.8+1.4 \mathrm{~L}$ ) during one test run using ISVVVH. Before and after ISVVVH, blood gases were analysed and $\mathrm{AaDO}_{2}, \mathrm{Va}$ / Qt, Qva/Qt, Qs/Qt were calculated. Intervals between test runs of ISVVVH were fixed on the basis of clinical data and indications of gas composition of the blood.

Results After ISVVVH test sequences all patients showed an increase of $\mathrm{PaO}_{2}$ by $18.8 \pm 3.2 \%(P<0.05)$ and a reduction of $\mathrm{Qs} / \mathrm{Qt}$ by $43.4 \pm 8.8 \% \quad(P<0.05)$. The average number of test runs in a single patient were $2.7 \pm 0.3$ with the time interval between 12 and $16 \mathrm{~h}$.

Conclusion ISVVVH showed improvement in pulmonary oxygenation in patients with peritonitis and acute respiratory failure.

\section{Reference}

1 Johnson D et al. Neutrophil-mediated acute lung injury after extracorporeal perfusion. J Thorac Card Surg 1994; 107: 1193.

\section{ABSTRACT NO. 26}

Granulocyte integrins upregulation and lymphocyte activation in cemented, reamed bone operations

E. Stamataki, E. Milo, D. Bajios, E. Pagoni, A. Kapsimali and A. Psarra

Evangelismos Hospital, Athens, Greece

Introduction In operations on bones, reaming and intramedullar cement pressurization are implicated in postoperative lung dysfunction as a result of microembolisation and leukocyte activation [1]. We deter- 
mined the expression of granulocyte (GC) integrins and lymphocyte (LC) T and B activation in reamed, cemented operations.

Methods In four groups of patients undergoing total hip and knee arthroplasty (THA, TKA), Thompson hemi-arthroplasty (TH) and Richards nailing (RN) as a control group, we measured GC integrins CD11a, CD11b and $\mathrm{LC}: \mathrm{T}(\mathrm{CD} 2+)$ and $\mathrm{B}(\mathrm{CD} 19+)$ percentages in whole blood by direct, double immunofluorescence and flow cytometry: (a) before reaming or nailing (b) $90 \mathrm{~min}$ later (c) $6 \mathrm{~h}$ after the 2nd sample and (d) $20 \mathrm{~h}$ later. ANOVA and factor analysis was used for statistical analysis.

Results Cells expressing the specific molecule are given as percentages of GC and LC. CD11b $\uparrow$ : TH $P<$

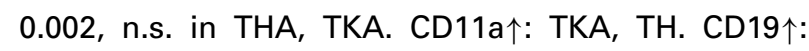
THA $P<0.01$, TKA $P<0.05$, n.s. in TH. Between groups: $\mathrm{CD} 11 \mathrm{~b}$ : TH $>\mathrm{R}, P<0.005$, THA $>$ TKA, $P<$ 0.000, CD11a $\uparrow:$ TKA $>$ TH. In RN CD11a, CD11b was down regulated and CD19+ cells unchanged (Fig. 1).

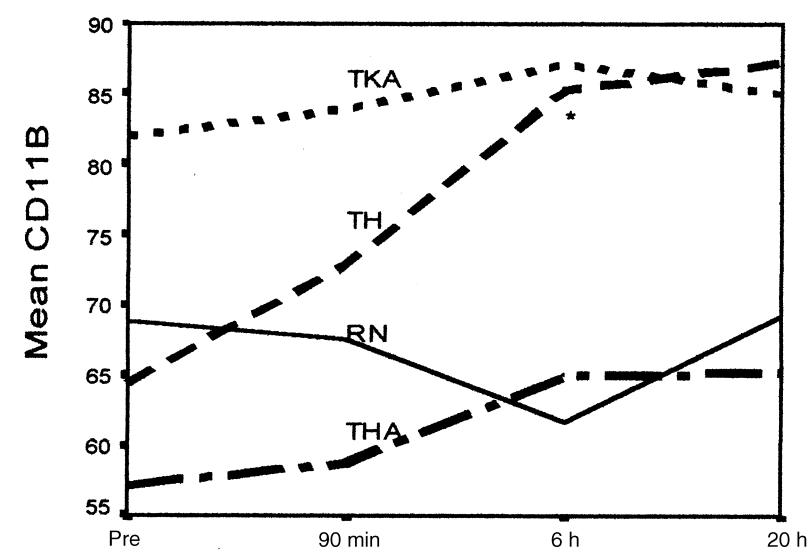

Fig. 1. GC integrin variation before and after major long bone surgery.

Conclusion GC activation in all cemented operations suggests reaming and intramedullar pressurization are the causes of the reported distal damage while the increase of CD19+ cells indicates stimulation of humoral immunity.

\section{Reference}

1 Andrew NP et al. Reamed femoral nailing in patients with multiple injuries. Clin Orthop 1997; 339: 41-46.
ABSTRACT NO. 27

Circulating blood volume after haemodialysis - analysis by using pulse dye-densitometry

T. lijima, M. Ohtake, T. Takagi, T. Tatara and Y. Iwao Department of Anesthesiology, Kyorin University School of Medicine Mitaka-City, Tokyo, Japan

Introduction Perioperative management of circulating blood volume (CBV) after haemodialysis (HD) is important to prevent hypotension occurring during anaesthesia [1]. Pulse dye-densitometry (PDD) is a newly developed method for monitoring cardiac output and circulating blood volume simultaneously by using a noninvasive technique to detect arterial indocyanine concentration. We examined the predicted value for haemodynamic derangement after $H D$.

Methods $\mathrm{CO}$ and CBV were measured by PDD before and after haemodialysis in 16 patients in the intensive care unit. Alteration of CBV was calculated from a change in haemoglobin concentration. Measured $\mathrm{CBV}$ values were compared with the predicted value from the haemoglobin concentration.

Results There was no correlation between predicted CBV changes calculated from the haemoglobin concentration and measured CBV values. Reduction of $\mathrm{CBV}$ after HD was closely correlated with the percentage reduction of $\mathrm{CO}$ (Fig. 1).

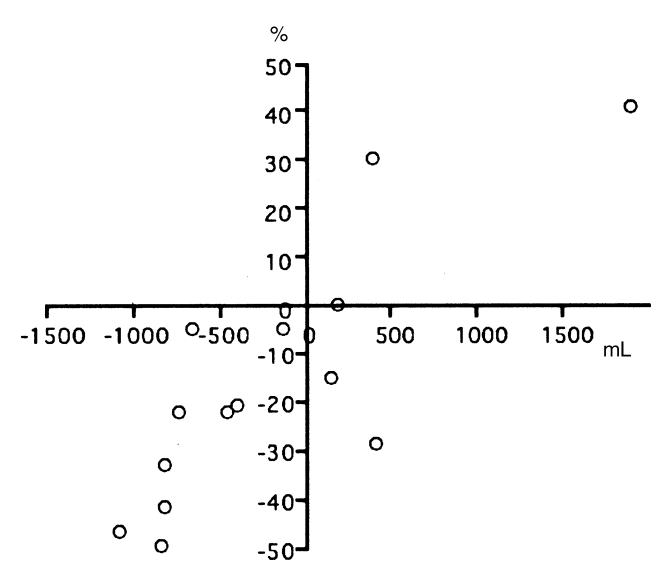

Fig. 1. Correlation between reduction of $\mathrm{CBV}$ and $\mathrm{CO}$ before and after haemodialysis. Abscissa: percentage reduction of cardiac output after haemodialysis, Ordinate: change in circulating blood volume after haemodialysis. 
Conclusion We found that a reduction of the CBV value is a reliable predictor of reduction of $\mathrm{CO}$. Haemoglobin concentration and calculated water balance are not predictors for reduction of $\mathrm{CO}$ after haemodialysis. Perioperative management of CBV guided by PDD may be useful to prevent unpredicted hypotension after induction of anaesthesia in haemodialysed patients.

\section{Reference}

1 Barker SJ. Blood volume measurement. The next intraoperative monitor? Anesthesiology 1998; 89: 1310-1312.

ABSTRACT NO. 28

Effect of urapidil on cerebral glucose utilization during rewarming of mild hypothermic rats

K. P. Ittner, J. Schonberger, M. Bucher, ChR. Eilles and J. Hobbhahn

University Hospital of Regensburg, D-93042 Regensburg, Germany

Introduction Urapidil (alpha-1 adrenergic antagonist/ 5-HT1A agonist) accelerates rewarming of patients with mild hypothermia [1]. 5-HT1A agonists interfere with glucose metabolism [2, 3]. We investigated the influence of urapidil on cerebral glucose utilization during rewarming after mild hypothermia.

Methods This is a prospective, randomized study in animals. Mild hypothermia of anaesthetized SpragueDawley rats (eight per group) was achieved by surface cooling $\left(33.2 \pm 0.5^{\circ} \mathrm{C}\right)$ and followed by two treatments: group 1: convective air rewarming; group 2: convective air rewarming after $5 \mathrm{mg} \mathrm{kg}^{-1}$ urapidil i. v. Brain glucose metabolism during the $20 \mathrm{~min}$ of rewarming was assessed by [18 F]2-fluoro-2-deoxy-Dglucose (FDG) and positron emission tomography (PET). FDG image sets consisted of five planes in the brain of each animal. Statistical analysis was performed with two-sided Student's $t$-test.

Results Twenty minutes of rewarming showed a significantly $(P<0.001)$ higher temperature in the animals treated with urapidil $\left(36.6 \pm 0.4^{\circ} \mathrm{C}\right)$ vs. control $\left(35.5 \pm 0.4^{\circ} \mathrm{C}\right)$. FDG uptake showed no statistical difference (urapidil: $0.589 \pm 0.1 \mu \mathrm{Ci} \mathrm{mL}{ }^{-1}$, control: $0.597 \pm$
$0.1 \mu \mathrm{Ci} \mathrm{mL}{ }^{-1}$ ). Blood glucose concentrations were not different.

Conclusion Acceleration of rewarming with urapidil did not increase glucose metabolism in the rat brain. This effect could be caused by the 5-HT1A agonistic activity of urapidil. 5-HT1A agonists inhibit the activity of hippocampal and cortical neurons in rodents [3].

\section{References}

1 Ittener KP, Bucher M, Bachfischer M, Grobecker HF, Hobbhahn J. The $\alpha 1$-adrenergic antagonist $/ \mathrm{H}^{-} \mathrm{T}_{1 \mathrm{~A}}$-agonist urapidil accelerates forced air rewarming of patients with mild hypothermia. Anesthesiology 1998; 89: A1332.

2 Chaouloff F, Jeanrenaud B. 5-HT1A and alpha-2 adrenergic receptors mediate the hyperglycemic and hypoinsulinemic effects of 8-hydroxy-2-(di-n-propylamino)tetralin in the conscious rat. J Pharmacol Exp Ther 1987; 243: 11591166.

3 Prehn JH, Backhaus C, Karkoutly C et al. Neuroprotective properties of $5-\mathrm{HT} 1 \mathrm{~A}$ receptor agonists in rodent models of focal and global cerebral ischemia. Eur $J$ Pharmacol 1991; 203: 213-222.

\section{ABSTRACT NO. 29}

\section{Recovery of cognitive function after total intravenous} anaesthesia vs. balanced anaesthesia

J. Kreienmeyer, L. O. Jauch and M. Arridt

University Hospital of Rostock, Germany

Introduction Recovery of cognitive function is a main factor of discharge from the PACU as well as from hospital after day-case surgery.

Methods We studied 37 patients aged 18-65years scheduled for minor gynaecological surgery randomized into four groups. Groups 1 and 2 received alfentanil $15 \mu \mathrm{g} \mathrm{kg}^{-1}$. In groups 3 and 4 a remifentanil infusion was started at a rate of $0.2 \mu \mathrm{g} \mathrm{kg} \mathrm{kgin}^{-1}$. Anaesthesia was induced 2 min later with propofol 1 $\mathrm{mg} \mathrm{kg}^{-1}$ in all groups and maintained with sevoflurane $1.2-1.8 \%$ end-tidal concentrations in group 1 and 3 , or propofol $0.15 \mathrm{mg} \mathrm{kg}^{-1}$ in group 2 and 4 as clinically required. The patients of group 1 and 2 received additional alfentanil $5 \mu \mathrm{g} \mathrm{kg}^{-1}$ as needed, the remifentanil infusion in group 3 and 4 was continued until the end of surgery. Cognitive function was assessed using 'Zahlenverbindungstest (ZVT)' [1], a modification of the trail making test which is sensitive for 
minimal cognitive dysfunction, performed by the same investigator before anaesthesia and 2 and $4 \mathrm{~h}$ after anaesthesia. After testing for normal distribution statistical analysis was performed with analysis of variance.

Results Patients in groups 2 and 4 awakened faster from anaesthesia than in the other groups $(P=0.037)$

(Table 1). Cognitive function assessed by ZVT returned to preanaesthetic values $2 \mathrm{~h}$ after anaesthesia. We even found a trend to improvement at $4 \mathrm{~h}$ in all groups.

Conclusion The choice of anaesthetics for minor gynaecological surgery can shorten turnover times in the operation theatre but has no influence on recovery of cognitive function.

\section{Reference}

1 Oswald WD, Roth E. Der Zahlenverbindungstest (ZVT), 2nd edn. Göttingen, Germany: Hogrefe-Verlag, 1987.

Table 1. Awakening times in four groups of patients

\begin{tabular}{lcccc}
\hline & Group 1 & Group 2 & Group 3 & Group 4 \\
\hline $\begin{array}{l}\text { Time until } \\
\text { awake (s) }\end{array}$ & 426 & 267 & 427 & 248 \\
SD (s) & 96 & 201 & 172 & 73 \\
\hline
\end{tabular}

\section{ABSTRACT NO. 30}

Regional cerebral oxygen saturation monitoring during anaesthesia for neurosurgical procedures

S. Matiatou, N. Palgimesi, P. Kould, G. Nicolaidou and L. Papadimitriou

Anaesthetics Department, Piraeus General Hospital and Aretalon Hospital of the University of Athens, Greece

Introduction Regional cerebral oxygen saturation $\left(\mathrm{rSO}_{2}\right)$ measured by near infrared spectroscopy (NIRS) has been used as an indirect method of cerebral blood flow and cerebral oxygen metabolism estimation [1]. The aim of this study was to monitor $\mathrm{rSO}_{2}$ changes in patients undergoing brain tumour resections.

Methods We studied 11 patients, ASA II-III, scheduled for neurosurgical procedures. Continuous invasive monitoring of systolic, diastolic, mean arterial pressure (SAP, DAP, MAP), arterial blood gases and noninvasive monitoring of $\mathrm{ETCO}_{2}$ and $\mathrm{SpO}_{2}$ was applied to all patients. Anaesthesia was induced with propofol and fentanyl, and maintained with $\mathrm{N}_{2} \mathrm{O} / \mathrm{O}_{2}$ and sevoflurane 1-1.5\%. A disposable sensor 3 100SD SomaSensor ${ }^{\circledR}$ was applied to the patient's forehead and connected to an INVOS ${ }^{R}$ cerebral oximeter. $\mathrm{rSO}_{2}$ was measured on arrival, before and immediately after intubation, at skin incision, at the opening of the dura, during surgical manipulations and at the end of the operation. Statistical analysis of $\mathrm{rSO}_{2}$ was performed with MANOVA and of MAP changes with ANOVA with repeated measures.

Results $\mathrm{rSO}_{2}$ values on arrival were 44-74 (mean 60.82, normal limits 55-75\%). There was no statistically significant difference in $\mathrm{rSO}_{2}$ among arrivals, after intubation and at the end of the operation. $\mathrm{rSO}_{2}$ decreased at the opening of the dura (mean 55. 9\%) and during surgical manipulations (mean 55.82\%) and this was both statistically $(P<0.05)$ and clinically significant. There was a statistically significant difference between MAP on arrival (mean $108 \mathrm{mmHg}$ ) and MAP during manipulations (mean $78.8 \mathrm{mmHg}$ ).

Conclusion Regional cerebral oximetry in patients undergoing brain tumour resections has shown a significant decrease in $\mathrm{rSO}_{2}$ values during the opening of the dura and surgical manipulations.

\section{Reference}

1 Williams IM et al. Cerebral hypoxia detected by near infrared spectroscopy. Anaesthesia 1994; 49: 762-766.

\section{ABSTRACT NO. 31}

The use of lornoxicam-meperidine combination for postoperative analgesia

M. Balanika, M. Tsitsika, W. Wilczynski, P. Giannakopoulos, N. Paparrizou and H. Plessia Department of Anaesthesia, Evangelismos General Hospital of Athens, Greece

Introduction Purpose of our study was to evaluate 
the efficacy of lornoxicam-meperidine combination in postoperative pain treatment [1].

Methods After written informed consent 30 patients aged 45-67, scheduled for elective lower abdominal surgery were studied. Anaesthesia was induced with propofol $2.5 \mathrm{mg} \mathrm{kg}^{-1}$ and maintained with propofol 5$6 \mathrm{mg} \mathrm{kg}^{-1} \mathrm{~h}^{-1}$ and remifentanil $0.5-1.5 \mu \mathrm{g} \mathrm{kg}^{-1} \mathrm{~min}^{-1}$. Thirty minutes before the end of the operation the patients were randomized to receive lornoxicam $8 \mathrm{mg}$ i.v. and meperidine $75 \mathrm{mg}$ i.m. (group I) or meperidine $75 \mathrm{mg}$ i.m. only (group II). Further postoperative analgesia included meperidine $50 \mathrm{mg}$ i. $\mathrm{m}$. (up to 6 doses over $24 \mathrm{~h}$ ) after the first request for postoperative pain relief. Group I received also Iornoxicam 8 $\mathrm{mg}$ i. v. $12 \mathrm{~h}$ after the end of the operation. Pain intensity (using VAS at $4 \mathrm{~h}$ and $24 \mathrm{~h}$ postoperatively), time to the first analgesic request (TR) and meperidine total number of doses required over $24 \mathrm{~h}$ were recorded. Adverse events (nausea, vomiting, bleeding) were recorded. Statistical analysis was performed using Student's $t$-test for independent and dependent samples $(P<0.05$ was considered significant).

Results There was no significant difference between groups regarding demographic data. Time to the first analgesic request (TR) and total number of doses of meperidine were significantly lower in group I. VAS scores at $4 \mathrm{~h}$ and $24 \mathrm{~h}$ postoperatively were comparable between groups (Table 1). One patient experienced nausea in group I, and 3 patients in group II. Abnormal perioperative bleeding was not observed in either groups.

Conclusion Lornoxicam-meperidine

combination provides efficacious postoperative analgesia and reduces opioid consumption.

Table 1. Effects of lornoxicam-meperidine on pain scores

\begin{tabular}{lcc}
\hline & Group I & Group II \\
\hline TR (min) & $187.33 \pm 29.2$ & $139.13 \pm 34.58$ \\
VAS 4 h & $32.66 \pm 14.5$ & $39.53 \pm 17.47$ \\
VAS 24 h & $30.33 \pm 8.75$ & $36 \pm 14.04$ \\
Total of meperidine doses $(n)$ & $3.26 \pm 1.22^{*}$ & $4.2 \pm 1.26$ \\
Nausea & $1 / 15$ & $3 / 15$ \\
Vomiting & $0 / 15$ & $1 / 15$ \\
\hline
\end{tabular}

${ }^{*} P<0.05$.

\section{Reference}

1 Stroissnig $\mathrm{H}$,. Frenzel W. Lornoxicam. A novel highly potent anti-inflammatory and analgesic agent. Clinical Investigators Brochure, 6th edn. Vienna, Austria: Hafslund Nycomed Pharma AG. 1992.

\section{ABSTRACT NO. 32}

The use of bispectral index (BIS) during induction of anaesthesia with sevoflurane $8 \%$ for laryngeal mask airway insertion

A. Dourna, C. Dimitropoulou and O. Hambouri

Anaesthesia Department, General Hospital of Athens 'G. Gennimatas', Greece

Introduction The bispectral index (BIS) is a new concept to study the depth of anaesthesia. BIS correlates with the anaesthetic effects of sevoflurane (S). The aim of our study was the comparison of the time needed for laryngeal mask airway insertion, as well as of the time of emergence between BIS-guided and non-BIS-guided anaesthesia.

Methods Forty-five patients, ASA I-III, 50-85 years of age, unpremedicated, scheduled for elective surgery under general anaesthesia were randomized into two groups in a prospective single-blind study. Patients in group $A(n=20)$ received single breath vital capacity inhalational induction with $\mathrm{S} 8 \%$ in $100 \% \mathrm{O}_{2}$ via a facemask (fresh gas flow $6 \mathrm{~L} \mathrm{~min}{ }^{-1}$ ). Laryngeal mask airway (LM) insertion was performed by the same anaesthesiologist in all groups. In group $A$ the anaesthesiologist was guided by her clinical experience while BIS was measured by an independent observer. Induction in group $\mathrm{B}(n=25)$ was the same but LM insertion was attempted when BIS index attained 60. Maintenance of anaesthesia was guided by clinical signs in group $A$, while in group $B$ volatile agent was adjusted to maintain a BIS index of 40-60. The time of LM insertion, end-tidal S (ET Sins $_{\text {) }}$ and BIS (BIS ins $_{\text {) }}$ during insertion $\mathrm{BIS}$ and $\mathrm{ET}_{\mathrm{S}}$ throughout the procedure as well as at the end of it (BIS end $\left.^{-} \mathrm{ET}_{\text {Send }}\right)$ and the time of emergence $\left(t_{e m}\right)$ were measured. Student's $t$ test was used for statistical analysis.

Results There were no significant differences between the two groups (Table 1).

Conclusion Although BIS is an accurate index of the level of hypnosis, when compared with clinical experience no difference of statistical importance has been found. 
Table 1. Time of emergence from BIS and non-BIS-guided anaesthesia

\begin{tabular}{lllllllll}
\hline \multicolumn{1}{c}{$\begin{array}{l}\text { Time } \\
\text { for LM } \\
\text { insertion } \\
\text { (min) }\end{array}$} & BIS $_{\text {ins }}$ & ET $_{\text {Sins }}$ & BIS $_{\text {end }}$ & $\mathrm{ET}_{\text {Send }}$ & $\begin{array}{l}\mathrm{T}_{\text {em }} \\
(\mathrm{min})\end{array}$ & $\mathrm{BIS}_{\mathrm{em}}$ \\
\hline $\begin{array}{c}\text { Group } \\
\text { A }\end{array}$ & 3.4 & 66 & 4.07 & 56 & 1.15 & 6.25 & 88 \\
$\begin{array}{c}\text { Group } \\
\text { B }\end{array}$ & 3.17 & 60 & 3.89 & 51 & 1.19 & 5.28 & 86 \\
$P \quad$ & 0.327 & 0.06 & 0.3 & 0.2 & 0.591 & 0.06 & 0.33 \\
\hline
\end{tabular}

groups. Tracheal intubation was associated with a significant increase in SBP and DBP in the $P$ groups, while in the PS groups there was a dose-dependent effect of sufentanil, which decreased the haemodynamic response to intubation. BIS values at the moment of intubation were similar in all $P$ and $P S$ groups.

Conclusion The results indicate that sufentanil can effectively prevent haemodynamic responses on intubation but BIS cannot predict movement at laryngoscopy nor the haemodynamic response to intubation. BIS does not reflect the depth of anaesthesia.
ABSTRACT NO. 33

\section{Bispectral index and blood pressure during induction and intubation \\ C. Vanlersberahe, M. H. Lauwers and F. Camu Flemish Free University of Brussels, Belgium}

Introduction The BIS index is a new monitor for the depth of anaesthesia. This study was performed to investigate whether BIS could predict the haemodynamic responses to laryngoscopy and intubation after induction with propofol and sufentanil.

Methods After approval by the Ethics Committee and informed consent, 36 unpremedicated patients, ASA I-II, 18-65 years, were randomly allocated into groups to receive target-controlled infusions of sufentanil $(0$, 0 . 5 , 1 or $1.5 \mathrm{ng} \mathrm{mL}^{-1}$ ) followed $5 \mathrm{~min}$ later by a target-controlled infusions of propofol $(1,2,4$ or $6 \mu \mathrm{g}$ $\mathrm{mL}^{-1}$ ). BIS index, heart rate, systolic and diastolic blood pressure were continuously recorded. ANOVA was used to analyse intragroup and intergroup data, respectively.

Results Patients' characteristics did not differ between groups. The BIS index values at loss of consciousness were significantly higher in the propofol + sufentanil (PS) groups compared with the propofol (P) groups. BIS decreased as propofol concentration increased. All patients in $\mathrm{P}$ group moved during laryngoscopy compared with none in the PS groups: BIS values at laryngoscopy were lower in the $P$

\section{ABSTRACT NO. 34}

Opioid $\mu$-agonists more strongly inhibit muscular than cutaneous pain in humans

M. Curatolo*, S. Petersen-Felix†, A. Gerber* and L. Arendt-Nielsen†

*Department of Anaesthesiology, Pain Therapy, University of Bern, Switzerland, and †Center for Sensory-Motor Interaction, Laboratory for Experimental Pain Research, University of Aalborg, Denmark

Introduction In experimental studies, drug-induced analgesia is usually assessed by cutaneous stimulation. If analgesics act differently on cutaneous and deep nociception, the results of these studies may not be entirely applicable to clinical pain involving deep structures. We tested the hypothesis that opioids have a different ability to inhibit cutaneous and muscular pain.

Methods Either the opioid remifentanil or placebo was infused in 12 healthy volunteers, in a cross-over fashion. Repeated electrical stimulation (five impulses at $2 \mathrm{~Hz}$ ) was applied at both skin and muscle. Pain thresholds were recorded.

Results Remifentanil caused a higher increase in the muscular pain thresholds than in the cutaneous pain thresholds $(P=0.035)$.

Conclusion Opioids more strongly inhibit muscular than cutaneous pain in humans. Because analgesics may affect differently cutaneous and deep nociception, and deep pain is present in most clinical pain 
states, the use of tests exploring deep pain in experimental studies is recommended.

ABSTRACT NO. 35

'Pain relief in labour and delivery': information on the world wide web

D. Harmon, M. Duggan, A. Westbrook and N. Flynn

University College Hospital, Galway, Ireland

Introduction The Internet is rapidly becoming a source of medical information. We undertook this study to assess the quality of information regarding pain relief in labour, particularly epidural analgesia.

Methods Using a home personal computer, a dial-up Internet Service Provider (Indigo, Ireland), six commonly used Internet search engines were queried using the search term 'pain relief in labour and delivery'. The first 20 sites listed by each search engine were assessed and each was scored on 24 items in four categories: Epidural description (A), Labour analgesia (B), Complications of regional anaesthesia (C), Anaesthesia for Caesarean section (D). Complete data on each item scored 2 points, inadequate data 1, item not mentioned 0 , and incorrect data scored -1 . Data is presented as median (range).

Results Each search engine yielded sites that scored well (Table 1). However, 66 (55\%) of the sites reviewed provided no information been sought.

Conclusion Although useful sites with accurate information on pain relief in labour are available on the Internet, simple search strategies fail to highlight these among weaker sites.

Table 1. Information retrieved by six web sites

\begin{tabular}{lllll}
\hline Web site & A & B & C & D \\
\hline Excite & $2(0-14)$ & $1(0-10)$ & $0(0-6)$ & $0(0-6)$ \\
Altavista & $0(0-14)$ & $2(0-10)$ & $0(0-12)$ & $0(0-10)$ \\
Hotbot & $0(0-10)$ & $0(0-10)$ & $0(0-12)$ & $0(0-12)$ \\
Lycos & $0(0-10)$ & $0(0-6)$ & $0(0-6)$ & $0(04)$ \\
Infoseek & $0(0-10)$ & $0(0-10)$ & $0(0-6)$ & $0(0-10)$ \\
Yahoo & $0(0-4)$ & $0(0-8)$ & $0(0-6)$ & $0(0-8)$ \\
\hline
\end{tabular}

ABSTRACT NO. 36

Isoflurane inhibits synaptic plasticity in mouse hippocampus

W. Simon*, G. Rammes†, G. Hapfelmeier*, W. Ziegansberger† and E. Kochs*

*Department of Anaesthesiology, Technische Universitat München, †Max-Planck-Institute of Psychiatry, Munich, Germany

Introduction Glutamate receptors play an important role in mediating synaptic transmission and synaptic plasticity in the CNS. Volatile anaesthetics depress glutamatergic transmission [1]. The effect of isoflurane (ISO) on long-term potentiation (LTP) as one form of synaptic plasticity was studied in the CAI region of mouse hippocampal slices.

Methods Extracellular recorded field excitatory synaptic potentials (fEPSPs) were evoked by afferent stimulation of the Schaffer-collaterals. To study the effect of ISO on the induction of LTP, fEPSPs were recorded in response to stimulation of the Schaffercollaterals with two independent inputs. The concentration of ISO was measured with gas chromatography.

Results Under controlled conditions, a tetanus (100 pulses, $100 \mathrm{~Hz}$ ) evoked reliable LTP in input 1 and potentiated fEPSP amplitude after $1 \mathrm{~h}$ to $155 \pm 13.4 \%$ $(P<0.001, n=9)$. However, in the presence of clinically relevant concentrations of ISO (0.2-0. $35 \mathrm{mMol})$, tetanizing input 2 with the same stimulus failed to induce LTP (100. $5 \pm 3.5 \%, n=9)$.

Conclusion The inhibition of LTP might be mediated by an ISO-induced depression of glutamatergic synaptic transmission. Since LTP is considered a cellular correlate of learning and memory [2], the inhibition of LTP by ISO could be involved in cognitive impairment after general anaesthesia.

\section{References}

1 Pearce RA, Stringer JL, Lothman EW. Effect of volatile anesthetics on synaptic transmission in the rate hippocampus. Anesthesiology 1989; 71: 591.

2 Bliss TVP, Collingridge GL. A synaptic model of memory: long-term potentiation in the hippocampus. Nature 1993; 361: 31-39. 


\section{ABSTRACT NO. 37}

Scalp and deep brain EEG evolution during anaesthesia induction with propofol

F. Gouvitsos*, M. Rey†, B. T. Njeef, J. C. Peragutł, N. Bruder* and F. Gouin*

*Department of Anaesthesiology, †Department of Clinical Neurophysiology, $\ddagger$ Department of Functional Neurosurgery, Timone Hospital Marseille, France

Introduction The use of EEG monitoring during neurosurgery is common. However, only scalp and cortex surface electrodes are usually used. The introduction of neuromodulation in the armamentarium of therapy for Parkinsonism has provided access to deep brain nuclei with multicontact electrodes used for stimulation. Provided with this neurophysiological and neuroanatomical controlled set-up, we compared the effect of propofol during anaesthesia induction on the EEG obtained from the scalp and the thalamic nucleus.

Methods After approval from our Ethical Committee and informed consent from the patients, six patients suffering from Parkinsonism who had agreed to undergo definite implantation of neuro-pacemakers after a positive test-phase, received propofol delivered by an automatic Diprifusor ${ }^{\circledR}$ pump during the induction of anaesthesia. The EEG was registered from both scalp electrodes and a Medtronic DBS$338728 \mathrm{~cm}$ thalamic positioned electrode. The signal was treated by nonlinear analysis and the correlation dimension (D2) was calculated according to the Grassberger Procaccia method [1]. Cortical D2 (CD1) and subcortical D2 (SCD2), and also calculated effectsite concentration (ESC) of propofol were registered just before induction (TO), when the patient lost consciousness (T1), when laryngoscopy was clinically possible (T2), just after intubation (T3), and $5 \mathrm{~min}$ later (T4).

Results Six patients (median age: $55 \pm 9$ years) were included in this study. CD2, SCD2 and ESC values are reported in Table 1. This study showed an early effect of propofol on cortical electric activity as compared with subcortical electric activity.

Conclusion This study shows that intubation becomes clinically possible when SCD2 joins CD2. It opens the question of the validity of isolated cortical or scalp EEG monitoring during neuroanaesthesia that might indicate silence whereas the subcortical
Table 1. Average values of CD2, SCD2 and ESC at T0, T1, $\mathrm{T} 2, \mathrm{~T} 3, \mathrm{~T} 4$

\begin{tabular}{llllll}
\hline & T0 & TI & T2 & T3 & T4 \\
\hline C & 9.6 & 5.8 & 5.6 & 6.4 & 6.1 \\
D2 & \pm 1.3 & \pm 1.7 & \pm 1.3 & \pm 13 & 0.9 \\
SC & 9.5 & 8.8 & 6.1 & 6.7 & 6.3 \\
D2 & \pm 1.2 & \pm 1.2 & \pm 1.3 & \pm 0.6 & \pm 0.9 \\
ESC & 0 & 2 & 6.4 & 7.1 & 7.0 \\
& & \pm 0.7 & \pm 2.9 & \pm 2.9 & \pm 2.8 \\
\hline
\end{tabular}

DCc: cortical correlation dimension.

DCsc: subcortical correlation dimension.

ESC: propofol effect-site concentration $\left(\mu \mathrm{g} \mathrm{mL}^{-1}\right)$.

nuclei still show activity. However, these results cannot be generalised since our model consists of only patients with Parkinsonism.

\section{Reference}

1 Rey M, Guillemant P. Contribution of non-linear mathematics (chaos theory) to EEG analysis. Neurophysiol Clin 1997; 27: 406-428.

\section{ABSTRACT NO. 38}

Does spectral edge frequency (SEF) reflect clinical decisions regarding anaesthetic drug dosage?

G. M. Gurinan, N. Weksler, M. Schily, M. Popescu and A. Porat

Soroka Medical Centre and Ben Gurion University, Anaesthesiology, Beer-Sheva, Israel

Introduction Early studies classified stages of anaesthesia based on SEF level, 8 to $12-13 \mathrm{~Hz}$ being considered the normal range during maintenance. The aim of this study was to correlate the clinical judgement of the anaesthesiologist with the SEF variability during general anaesthesia in different clinical situations. Methods ASA 1 and 2 patients scheduled either for soft tissue and orthopaedic procedures (the 'general surgery' group $A$ ); Caesarean section (B); or gastric banding $(C)$ for morbid obesity were included in the study. After diazepam premedication and fentanylthiopental-suxinylcholine for intubation, all patients received isoflurane $0.5-1.5 \%, \mathrm{~N}_{2} \mathrm{O}: \mathrm{O}_{2} 2: 1$, fentanyl for 
maintenance of anaesthesia and vecuronium for muscle paralysis. SEF was monitored by using a processed EEG device that recorded the data on a 4-s epoch. The SEF screen was kept away from the view of the anaesthesiologist in charge of the patient and no EEG data influenced his/her decision regarding the dosage of anaesthetic drugs. Intraoperative SEF was then analysed and the total time it remained 'in range' $(8-12 \mathrm{~Hz})$ was calculated for each group. The cases in which SEF remained in range for more than $80 \%$ of the general anaesthesia maintenance time were also identified.

Results The percentage of the total time SEF stayed in range was $87 \%$ for the general surgery group (A), $15 \%$ for Caesarean section (group B) and $68 \%$ in the obesity group (C). Table 1 shows the percentage of patients in each group for whom SEF remained in range more than $80 \%$ of the maintenance time.

Conclusion The study offers an electrophysiological confirmation of well-known facts regarding the anaesthesiologist's reluctance to increase the anaesthetic dosage in some special cases, e.g. Caesarean section (where the fetal condition and uterine tone prevail), or in obese patients, where the criteria for drug dosage is ambivalent.

Table 1. Distribution of electrophysiological responses above and below SEF $8-12 \mathrm{~Hz}$ in three groups of patients

\begin{tabular}{llll}
\hline Patients & $n$ & $\begin{array}{l}\text { SEF } 8-12 \mathrm{~Hz} \\
>80 \%\end{array}$ & $\begin{array}{l}\text { SEF 8-12 Hz } \\
<80 \%\end{array}$ \\
\hline Group A & 39 & 35 & 4 \\
Group B & 55 & 13 & 42 \\
Group C & 71 & 38 & 33 \\
\hline
\end{tabular}

$\mathrm{A}, \mathrm{B} P<0.0001 ; \mathrm{B}, \mathrm{C} P<0.001 ; \mathrm{A}, \mathrm{C} P<0.0001$.

ABSTRACT NO. 39

Stability of a sufentanil citrate-ropivacaine mixture in a portable pump reservoir

G. Brodner, M. A. E. Marcus, H. Buerkle, T. Mollhoff and $\mathrm{H}$. Van Aken

Klink und Poliklinik für Anästhesiologie der Westfälischen Wilhelms Universität Münster, Germany

Introduction Due to absorption, a sufentanil mixture might be unstable in medical reservoirs containing PVC [1,2]. We analysed the stability of sufentanil in a mixture with ropivacaine $0.2 \%$ in a $750-\mathrm{mL}$ reservoir. This solution, used for patient controlled epidural analgesia, is typically infused over a period of $96 \mathrm{~h}$. It is prepared by the pharmacist and can be stored for up to 4 weeks at a temperature of $8^{\circ} \mathrm{C}$.

Methods During simulated infusions of $5 \mathrm{mLh}^{-1}$ at a temperature of $25^{\circ} \mathrm{C}$, sufentanil concentrations were measured for $96 \mathrm{~h}$. Samples were taken from the reservoir and the catheter tip under the following conditions: glass or PVC reservoir containing ropivacaine $0.2 \%$ and $\mathrm{I} \mu \mathrm{g} \mathrm{mL}-1,0.75 \mu \mathrm{g} \mathrm{mL}^{-1}$ or $0.5 \mu \mathrm{g}$ $\mathrm{mL}^{-1}$ sufentanil (Glass I $\mu \mathrm{g} \mathrm{mL}^{-1}$, Glass $0.75 \mu \mathrm{g} \mathrm{mL}^{-1}$, Glass $0.5 \mu \mathrm{g} \mathrm{mL}^{-1}$, PVC I $\mu \mathrm{g} \mathrm{mL}^{-1}$, PVC $0.75 \mu \mathrm{g} \mathrm{mL}^{-1}$, PVC $0.5 \mu \mathrm{g} \mathrm{mL}^{-1}$ ) and PVC reservoir with ropivacaine $0.2 \%$ and $\mathrm{I} \mu \mathrm{g} \mathrm{mL}^{-1}$ sufentanil, which has been stored for 4 weeks by $80^{\circ} \mathrm{C}$ (PVC-4 weeks, $1 \mu \mathrm{g} \mathrm{mL}^{-1}$ ).

Results Correlations between the concentrations at the different time points were extremely high for the reservoir $\left(r_{\min }=0.98, r_{\max }=1.00\right)$ and for the catheter tip $\left(r_{\min }=0.86, r_{\max }=1.00\right)$. ANOVA revealed no difference in sufentanil concentrations between glass, PVC and PVC after storage of 4 weeks for independent samples of the same solutions (Fig. 1).

Conclusion Sufentanil citrate in concentrations between 1 and $0.5 \mu \mathrm{g} \mathrm{mL}{ }^{-1}$ remains stable in a PVC reservoir in an admixture of ropivacaine $0.2 \%$ over $96 \mathrm{~h}$. There is no change in the concentration if the reservoir is stored over 4 weeks at $8^{\circ} \mathrm{C}$.

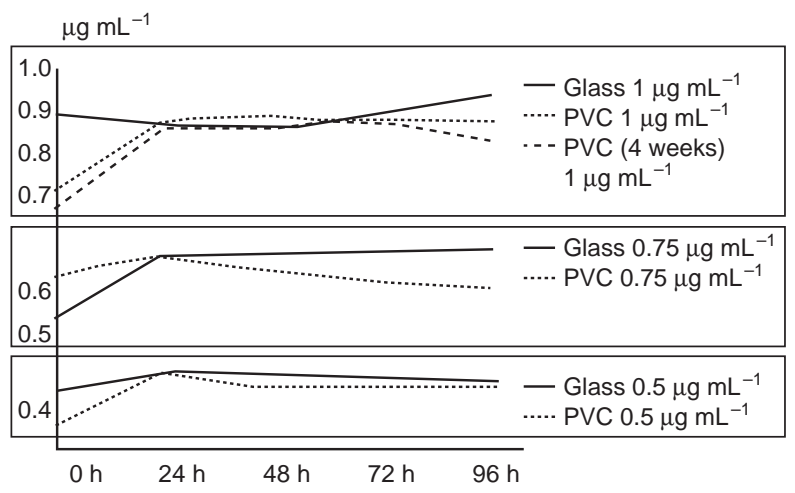

Fig. 1. Sufentanil concentration: catheter tip. 


\section{References}

1 Brouwers JRBJ et al. EMP 1995; 1: 12-14.

2 Roos PJ, Glerum JH, Schroeders MJ. Effect of glucose $5 \%$ solution and bupivacaine hydrochloride on absorption of sufentanil citrate in a portable pump reservoir during storage and simulated infusion by an epidural catheter. PWS 1993; 15: 269-275.

ABSTRACT NO. 40

Epidural ropivacaine and clonidine vs. ropivacaine alone as rescue analgesic regimens after thoracic and major abdominal surgery

S. Mentzelopoulos, C. Romana, M. Tzoufi, D. Corolanoglou and E. Karamichali

Evangelismos General Hospital, Athens, Greece

Introduction The purpose of this double-blind, placebo-controlled, randomized, prospective study was to compare the analgesic effects of single rescuedoses of $0.2 \%$ ropivacaine $(1-2 \mathrm{~mL}$ per segment) plus clonidine $(50 \mu \mathrm{g})$ and $0.2 \%$ ropivacaine $(1-2 \mathrm{~mL}$ per segment) plus saline (placebo).

Methods Within a 1-year period, 34 ASA II-III, postanaesthesia care unit patients receiving continuous epidural analgesia via infusion pump (Baxter Infusor LV 5) after thoracic or major abdominal surgery, were randomly allocated to either the ropivacaine-clonidine $(\mathrm{R}-\mathrm{C})(n=18)$ or the ropivacaine-placebo (R-P) $(n=16)$ rescue-dose groups. Inclusion criteria were: (a) confirmed failure of the infusion pump containing the initially prescribed analgesic regimen (b) visual analogue scale (VAS score $\geq 25 \mathrm{~mm}$ ), and (c) increasing patient discomfort within the last $60 \mathrm{~min}$. Both groups received a $1-2 \mathrm{~mL}$ per segment bolus of $0.2 \%$ ropivacaine (dose adjusted to patient height). In addition, the $\mathrm{R}-\mathrm{C}$ group received $50 \mu \mathrm{g}$ of clonidine in 1 $\mathrm{mL}$ saline, while the $\mathrm{R}-\mathrm{P}$ group received $1 \mathrm{~mL}$ saline (placebo). The VAS scores at rest, and during voluntary deep breathing and coughing were recorded just prior to rescue dose-administration and 30,45 and 60 min thereafter. The median VAS values after the rescue dose were used in the subsequent data analysis. The time from the end of the operation until rescuedose administration ('postoperative time'), the arterial pressure, heart rate, respiratory rate, and the additional crystalloid, colloid and vasopressor require- ments were recorded as well. Parametric and nonparametric data were compared between the groups with Student's paired t-test and the MannWhitney $U$-test, respectively. Significance was accepted at $P<0.05$.

Results The demographic data, 'prerescue' VAS scores and respiratory rates, 'rescue times', doses of ropivacaine, and fluid and vasopressor requirements did not differ significantly between the groups. In addition, the recorded haemodynamic parameters did not differ between the groups (apart from the systolic pressures recorded $45 \mathrm{~min}$ postrescue dose, which were significantly lower in the R-C group, $P<$ 0.05). In both groups, mean arterial pressure and heart rate were maintained $>60 \mathrm{mmHg}$ and 45 beats per min, respectively. The 'postrescue' respiratory rates and VAS scores at rest and during increased inspiratory effort were significantly lower in the R-C group $(P<0.05)$; the VAS scores during voluntary coughing, although lower in the $\mathrm{R}-\mathrm{C}$ group, did not reach significance $(P=0.08)$.

Conclusion The addition of $50 \mu \mathrm{g}$ clonidine to a rescue-dose of ropivacaine provides superior analgesia to ropivacaine alone in conjunction with an acceptable haemodynamic profile.

\section{ABSTRACT NO. 41}

Minimum anaesthetic concentration (MAC) of isoflurane with different xenon concentrations in swine

K. Hecker, M. Reyle-Hahn, J. H. Baumert, N. Horn, D. Eletr and R. Rossaint University Hospital of RWTH Aachen, Germany

Introduction The anaesthetic properties of xenon were investigated in different settings [1]. For patients requiring a fraction of inspired oxygen $\left(\mathrm{FiO}_{2}\right)>0.3$, the use of xenon as the sole anaesthetic is limited due to a high minimum anaesthetic concentration (MAC) of $71 \%$. This warrants investigating the combination of xenon with other inhalational agents compared with nitrous oxide use [2]. In this study, the influence of several concentrations (0-65\%) of inhaled xenon on the MAC for isoflurane was investigated.

Methods The study was performed in 10 pigs (weight $28-35 \mathrm{~kg}$ ) anaesthetized with propofol and, after orotracheal intubation, normoventilated with xenon $0-15-30-40-50-65 \%$ in oxygen. With each 
xenon concentration, isoflurane was gradually increased in five and decreased in the other five animals. Presence of a withdrawal reaction to a supramaximal pain stimulus (claw clamp) was recorded for each concentration [3]. The isoflurane MAC was calculated as the end-tidal concentration at which $50 \%$ of the individuals showed a reaction.

Results Under stable ventilation, haemodynamics, and temperature isoflurane MACs were: $1.82 \%$ for $0 \%$ $\mathrm{Xe}, 1.79 \%$ for $15 \% \mathrm{Xe}, 1.69 \%$ for $30 \% \mathrm{Xe}, 1.59 \%$ for $40 \% \mathrm{Xe}, 1.2 \%$ for $50 \% \mathrm{Xe}$, and $1.15 \%$ for $65 \% \mathrm{Xe}$.

Conclusion The isoflurane MAC is decreased by inhalation of xenon in a similar way as nitrous oxide. The effect seems to be nonlinear as the isoflurane MAC is decreased by $0.03-0.23 \%$ end-tidal isoflurane between 0 and $40 \%$ xenon but by $0.53 \%$ to $0.67 \%$ between 50 and $65 \%$. Thus, a combination of xenon with isoflurane may prove valuable for patients requiring an $\mathrm{FiO}_{2}>0.3$.

\section{References}

1 Franks NP, Dickinson R, de Sousa SLM, Hall AC, Licb WR. How does xenon produce anaesthesia? Nature 1998; 396: 324.

2 Cole D. J. The nonlinear potency of sub-MAC concentrations of nitrous oxide in decreasing the anesthetic requirement of enflurane, halothane, and isoflurane in rats. Anesthesiology 1990; 73: 93-99.

3 Eger El II. Minimum alveolar concentration of I-653 and isoflurane in pigs: Definition of a supramaximal stimulus. Anesth Analg 1988; 67: 1174-1176.

\section{ABSTRACT NO. 42}

\section{Comparison of propofol and sevoflurane for laryngeal mask airway (LMA ${ }^{\mathrm{TM}}$ ) insertion}

I. Kati, C. B. Demirel and U. A. Huseyinoglu

Yuzuncu Yil University, Turkey

Introduction $\mathrm{LMA}^{\mathrm{TM}}$ is a popular alternative to tracheal intubation during general anaesthesia. Insertion of the $L_{M A}{ }^{T M}$ requires suppression of upper airway reflexes and jaw relaxation. The purpose of this study was to compare propofol and sevoflurane for LMA ${ }^{T M}$ insertion.

Methods With our institutional Ethics Committee approval, ASA I adult patients, aged 20-40years, scheduled for elective orthopaedic surgery under general anaesthesia using the $\mathrm{LMA}^{\mathrm{TM}}$ were studied. The patients were randomly assigned to one of two induction protocols: (a) Propofol $2.5 \mathrm{mg} \mathrm{kg}^{-1}+2 \mu \mathrm{g}$ $\mathrm{kg}^{-1}$ fentanyl, and (b) sevoflurane $6 \%$ in $\mathrm{N}_{2} \mathrm{O}+\mathrm{O}_{2}+2$ $\mu \mathrm{g} \mathrm{kg}{ }^{-1}$ fentanyl. After loss of consciousness, the $\mathrm{LMA}^{\mathrm{TM}}$ was inserted by an anaesthesiologist. Degree of jaw opening, ease of $\mathrm{LMA}^{\mathrm{TM}}$ insertion, and degree of coughing, and gagging were graded in severity on a 0-2 point scale [1]. The number of attempts at $\mathrm{LMA}^{\mathrm{TM}}$ insertion and incidences of upper airway obstruction and postoperative sore throat were also recorded.

Results All results are reported as a mean \pm SD (Table 1). No statistically significant differences between groups were found. All patients in the sevoflurane group maintained spontaneous breathing prior to $\mathrm{LMA}^{\mathrm{TM}}$ insertion, whereas, patients receiving i.v. induction drugs experienced transient apnoea requiring assisted positive pressure ventilation in 22 of 30 patients.

Conclusion The present study demonstrates that the two groups are equally acceptable for $\mathrm{LMA}^{\mathrm{TM}}$ insertion. However, sevoflurane provides the benefit of maintaining spontaneous breathing throughout the induction period.

Table 1. Propofol or sevoflurane for LMA insertion

\begin{tabular}{lll}
\hline & $\begin{array}{l}\text { Propofol } \\
(n=50)\end{array}$ & $\begin{array}{l}\text { Sevoflurane } \\
(n=50)\end{array}$ \\
\hline Jaw opening & $0.15 \pm 0.38$ & $0.14 \pm 0.22$ \\
Ease of insertion & $0.06 \pm 0.20$ & $0.08 \pm 0.25$ \\
Coughing & 0.00 & $0.01 \pm 0.10$ \\
Gagging & 0.00 & 0.00 \\
Airway obstruction & 0.00 & 0.00 \\
Postoperative sore throat & $0.05 \pm 0.26$ & $0.06 \pm 0.15$ \\
Number of attempts & 1.00 & 1.00 \\
\hline
\end{tabular}

ABSTRACT NO. 43

\section{Interaction of sufentanil and propofol on loss of con- sciousness}

C. Vanlersberghe, M. H. Lauwers and F. Camu Flemish Free University of Brussels Medical Center, Belgium Introduction Propofol is often combined with sufen- 
tanil during total intravenous anaesthesia. The interaction between propofol and alfentanil during induction has already been characterised [1]. This study was designed to investigate the effect of different target effect-site concentrations of sufentanil on the propofol effect-site concentration required for loss of consciousness (LOC) and the produced changes in bispectral index.

Methods Following institutional approval and informed consent we studied 36 female patients, ASA I-II, 18-55 years. They were randomly allocated to receive an individual combination of sufentanil $(0$, 0.5 , 1 or $1.5 \mathrm{ng} \mathrm{mL}^{-1}$ ) and propofol $(1,2,4$ or $6 \mu \mathrm{g}$ $\mathrm{mL}^{-1}$ ) target effect-site concentrations using a computer-controlled infusion device. Study endpoint was LOC, tested by lack of response to verbal command. HPLC assay of both drugs in arterial blood samples allowed estimation of their effect-site concentration. The bispectral index values at LOC were also recorded. Data were analysed using ANOVA.

Results Patients' characteristics were comparable among the different treatment groups. The LOC occurred at lower effect-site concentrations of propofol and higher bispectral index values with increasing sufentanil effect-site concentrations. The mean arterial propofol concentrations were also lower with increasing sufentanil concentrations.

Conclusion Our results suggest that sufentanil pretreatment potentiates the effects of propofol to achieve the hypnotic endpoints at higher bispectral index values and lower propofol concentrations.

\section{Reference}

1 Vuyck J. Pharmacodynamic interaction between propofol and alfentanil when given for induction of anesthesia. Anesthesiology 1996; 84: 288-299.

\section{ABSTRACT NO. 44}

Intraocular pressure after peribulbar anaesthesia in patients with glaucoma

A. Zaliwa, J. M. Rouxel and J. P. Haberer

Hotel Dieu, Paris, France

Introduction Peribulbar block (PB) for intraocular surgery increases intraocular pressure (IOP) [1]. This IOP increase could be detrimental in patients with glau- coma. This study examined the effects of PB on IOP in patients with and without glaucoma.

Methods In 25 patients with glaucoma (G) and 36 patients with cataract (C) a PB was performed with $12 \mathrm{~mL}$ of a mixture of $2 \%$ lidocaine, $0.5 \%$ bupivacaine and hyaluronidase $16 \mathrm{~mL}$ inferotemporally, $6 \mathrm{~mL}$ superonasally). IOP was measured with a Tonopen $\mathrm{XL}$ applanation tonometer before (PO), immediately after the last superior injection (P1), and $10 \mathrm{~min}$ after ocular compression (P2). Pre- and postinjection IOPs were compared in each group and between the groups using a paired and unpaired Student's $t$-test.

Results IOP variations in the two groups are summarized in Fig. $1\left({ }^{*} P<0.01\right)$. In the $\mathrm{G}$ group, IOP increased from $27.4 \pm 6$ to $39.4 \pm 9 \mathrm{mmHg}$ (range 2354) after the PB and decreased to $16.9 \pm 5 \mathrm{mmHg}$ (range 7-23) after compression. The magnitude of the IOP variations expressed in percentages were identical between the two groups.

Conclusion PB is safe in patients with glaucoma.

\section{Reference}

1 O'Donoghue E. et al. Effect on intraocular pressure of local anaesthesia in eyes undergoing intraocular surgery. Br J Ophthalmol 1994; 78: 605-607.

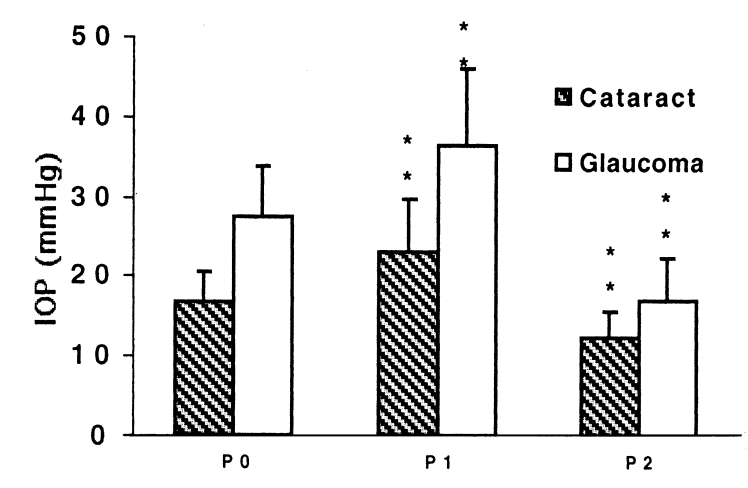

Fig. 1. IOP in patients with glaucoma or cataract receiving peribulbar block. 
ABSTRACT NO. 45

\section{Efficiency of regional analgesia in labour}

S. Rutter*, S. Comara†, C. Skinner* and R. Russell*

*John Radcliffe Hospital, Oxford, UK, and †Milton Keynes General Hospital, UK

Introduction Epidural service in labour varies between European countries [1,2]. $90 \%$ of the UK hospitals currently provide a $24-\mathrm{h}$ service with an average epidural rate of $24 \%$ [3]. In a prospective study we assessed efficiency of 200 regional blocks in labour in two hospitals in the Oxford region with different workload and manpower.

Methods Both participating hospitals ( $\mathrm{H} 1$ and $\mathrm{H} 2$ ) provide 24-h epidural service in labour. Delivery rate per year is 6500 in $\mathrm{H} 1$ and 3200 in H2. In each hospital 100 consecutive blocks in labour were studied. Anaesthetists recorded time of maternal request $\left(T_{R}\right)$, being informed $\left(T_{1}\right)$, attending the woman $\left(T_{A}\right)$, time and effect of loading dose $\left(T_{L}\right)$, technique and agents used.

Results Dedicated anaesthetic cover was available in $\mathrm{H} 1$, but was shared in $\mathrm{H} 2$. Maternal request was the main indication for $91 \%$ of blocks in labour. The median interval $\mathrm{T}_{\mathrm{R}-} \mathrm{T}_{1}$ was $5 \mathrm{~min}$ (range $0-155 \mathrm{~min}$ ). $72 \%$ of women were attended within $30 \mathrm{~min}$ of requesting an epidural (median interval $\mathrm{T}_{\mathrm{R}}-\mathrm{T}_{\mathrm{A}} 20 \mathrm{~min}$, range 0-120 $\mathrm{min})$. The common causes for delays were anaesthetists or midwives being busy. Median interval $T_{R}-T_{L}$ was $43 \mathrm{~min}$ (range 10-210 min). Epidural blocks were used in $99 \%$ of women, using low concentration local anaesthetic with or without fentanyl. In $85 \%$ of women analgesia was achieved within $30 \mathrm{~min}$. There was no significant difference in service efficiency between two participating hospitals but the number of regional blocks in labour per day: 5.9 in $\mathrm{H} 1$ and 1.6 in $\mathrm{H} 2$.

Conclusion Despite different workload and manpower between hospitals, high standards of delivering regional analgesia on-demand to women in labour are achievable in most cases. Time from mother's request to attending and administering a loading dose can be used as markers of efficiency of regional analgesia service in labour.

\section{References}

1 Clergue $\mathrm{F}$ et al. French survey of anaesthesia in 1996. Anesthesiology 1999; 91: 1509-1520.
2 Stamer UM et al. Practice of epidural analgesia for labour pain: a German survey. Eur J Anesthesiol 1999; 16: 308314.

3 Burnstein R et al. A survey of epidural analgesia for labour in the United Kingdom. Anaesthesia 1999; 7: 634-640.

ABSTRACT NO. 46

Sensitivity and specificity of the preoperative screening questionnaire

R. Rikker, L. Szudi and M. Wiedeman

Teaching Hospital of Szekszard, Hungary

Introduction Preanaesthetic assessment is an essential component of safe anaesthetic practice [1,2]. We compared the results of a questionnaire submitted to a nurse assistant and of examinations conducted by a staff anaesthetist.

Methods Five-hundred-and-thirty-seven patients were assessed at the preanaesthetic clinic over 5 weeks. These patients completed a preoperative screening questionnaire consisting of 40 questions with aid from nursing personnel. An anaesthetist also examined every patient. Specificity and sensitivity was evaluated both of the questionnaire and each question.

Results The overall sensitivity was $87.5 \%$, the specificity was $93.3 \%$, but $<40$ years of age the sensitivity was $69 \%$ and specificity was $97.6 \%$. Over 40 years the sensitivity was $93 \%$ and the specifity was $85.4 \%$. Differences were evenly divided between ASA I-II and III-IV patients. We present the sensitivity and specificity of each question.

Conclusion If completed, this questionnaire gives sufficient information about patients < 40 years before operation and only in case of positive answers is there a need for an assessment by a staff anaesthetist. Hence, the staff anaesthetist could spend more time in the operating theatre, so cost-effectiveness may increase. Furthermore this questionnaire calls anaesthetists' attention to the medically compromised patients in all cases.

\section{References}

1 Badner N, Craen R. Anaesthesia preadmission assessment: a new approach through use of a screening questionnaire. Can J Anaesth 1998; 45: 87-92. 
2 Lee A, Lum M. E. Risk of unanticipated intraoperative events in patients assessed at a preanaesthetic clinic. Can J Anaesth 1997; 44: 946-954.

\section{ABSTRACT NO. 47}

Selection criteria for patients undergoing an anaesthesia in the day hospital: risk estimation of ambulatory anaesthesia (Score de Risque Anesthésique Ambulatoire: SCORAA)

O. Abossolo, A. Debaert and PH. Scherpereel

University Regional Hospital of Lille, France

Introduction In the Regional University Hospital ( $\mathrm{CHRU}$ ) of Lille, we have seen a great increase in surgical and medical procedures performed with anaesthesia as out-patients. Many recommendations have dealt with the principles relative to the patient's admission and to the safety of the short-term hospitalisation [1]. Many criteria are predicative of the reliability of ambulatory procedures, and they may be classified into three different groups: medico-surgical procedures (criteria evaluated by the operator during the consultation), patients (criteria evaluated by the anaesthetist during the consultation), and discharge conditions [2,3]. We devised a risk estimation of ambulatory anaesthesia, or SCORAA, in order to evaluate all these criteria as a simple scoring system.

The SCORAA: The different risk levels for each criterion are represented by four colours: green (minor risk), orange (medium risk), red (major risk), black (risk excluding an operation under ambulatory anaesthesia). The risk of an operation under ambulatory anaesthesia is determined according to the distribution of colours, knowing that only one black square excludes the intervention. A prospective study on 500 patients treated in the Ambulatory Surgery Department, CHRU of Lille, will allow us to determine a scale of global risk for different colour distributions and to check the reliability of this tool in the assessment of the risks of ambulatory anaesthesia.

\section{References}

1 Wetcher BV. Ambulatory anaesthesia: which procedures, which patients? L'Opéré Ambulatoire, Congrés JEPU, 1999.

2 Société Française d'Anesthésie et de Réanimation (SFAR). Recommandations concemant $\gamma^{\prime}$ anesthésie du patient ambulatoire. September, 1994.
3 Venneman I. Critères de sélection des patients pour une intervention chirurgicale ou une intervention à visée diagnostique en hôpital de jour. Liège, 1998.

\section{ABSTRACT NO. 48}

Quality of the anaesthetic record: evaluation in a university hospital

A. Steib, C. Gros, C. Oltean, H. Schlotterbeck, S. Soulas and J. P. Dupeyron University Hospital of Strasbourg, France

Introduction A new anaesthetic chart allowing pre-, intra- and postoperative assessment of the anaesthetized patient was introduced in our university hospital on January 1999. The aim of this study was to analyse the quality of chart completion 10 months following its routine use.

Methods Records collected during November 1999 were retrospectively evaluated. A compendium of 56 items including identification of the patient and the procedure $(n=6)$, preoperative evaluation $(n=21)$, intraoperative management $(n=21)$ and basic recovery parameters $(n=9)$ was established. Residents participated actively in the study. Each item could be qualified as correct, absent, unreadable or not applicable. A $\chi^{2}$ test was used to compare surgical and nonsurgical procedures in emergency or elective situations.

Results Overall 1190 anaesthetic charts corresponding to 66640 items were analysed. The mean level of correct completion was $82 \%$ before recovery, and was $64.5 \%$ for the recovery parameters $(P<0.01)$. Identification was better recorded than the pre- and intraoperative periods $(94 \%$ vs. $75 \%$ and $86 \%$, respectively). Completion was higher during elective procedures $(85 \%)$ compared with emergency situations (72\%, $P<0.01$ ). Concerning recovery, some items were poorly completed in the areas of ventilation and pain. Discrepancies were noted between different units and recovery rooms.

Conclusion The quality of the anaesthetic records needs to be improved in order to allow better information between everyone involved in the care of patients. However, some missing parameters could be ascribed to problems of ergonomics: this has led us to a slight modification of the anaesthetic chart for the next printing. 
ABSTRACT NO. 49

\section{A model for the calculation of optimal or end time \\ F. Boer \\ OR Centre, Leiden University Medical Centre, The Nether- lands}

Introduction Operating room (OR) end times are connected to costs from either under-utilization or from overtime. The aim of this study was to develop a model to analyse OR utilization, with which optimal OR end times could be estimated with a view to minimize cost.

Methods The end times of three specialities in the OR cluster for head and neck surgery measured over three months were tabulated in a cumulative frequency table, using 15-min bin blocks. The cumulative percentage data were characterized by the equation $P_{T}=100 \times\left[T^{n} /\left(T^{n}+T_{50}^{n}\right)\right]$, in which $P_{T}$ is the percentage of time that the OR has ended at time $T$, $\mathrm{T}_{50}$ is the time by which $50 \%$ of ORs has ended and $n$ is a power value. The values of $T_{50}$ and $n$ were found by an iterative fitting procedure. From these results the optimal end time $\mathrm{T}_{50}$, OPT was found by iteratively changing $\mathrm{T}_{50}$, keeping $n$ constant until the total costs of overtime and under-utilisation were minimised. The costs of under-utilisation were calculated by multiplying the percentage of days the OR had finished by $16.30 \mathrm{~h}$, the number of personnel involved ( 2 operating nurses and 1 anaesthesia nurse) and the mean hourly payment. Similarly the costs of overtime were calculated, but these costs were multiplied by two as a penalty for overtime.

Results The $T_{50, \text { realised }}$ for neurosurgery was higher than the $T_{50, o p t i m a l}$, suggesting that excessive overtime costs were incurred. Both the $T_{50 \text {,realised for }}$ ophthalmology and ENT was less than $T_{50, o p t i m a l}$, suggesting that more operations should be scheduled per working day for optimal OR utilization (Table 1).

Table 1. Operating room end times in different settings

\begin{tabular}{llll}
\hline & Neurosurgery & Ophthalmology & $\begin{array}{l}\text { Otorhino- } \\
\text { laryngology }\end{array}$ \\
\hline $\mathrm{T}_{50, \text { realised }}$ & $15.31 \mathrm{~h}$ & $13.44 \mathrm{~h}$ & $14.11 \mathrm{~h}$ \\
$n$ & 13.6 & 17.8 & 15.1 \\
$\mathrm{~T}_{50, \text { optimal }}$ & $15.01 \mathrm{~h}$ & $15.14 \mathrm{~h}$ & $15.06 \mathrm{~h}$ \\
\hline
\end{tabular}

Conclusion By application of a logistic function to the cumulative percentage of OR end times and an iterative cost minimisation procedure, the optimal end time of the OR's of different surgical specialities can be estimated.

ABSTRACT NO. 50

The comparative obstetric mobile epidural trial (C.O.M.E.T.). Ambulatory epidural analgesia, delivery mode and pain relief: a randomized controlled trial

The C.O.M.E.T. Study Group, UK

$\dagger$ Birmingham University Departments of Public Health and Epidemiology and Anaesthesia; *Leicester Royal Infirmary Departments of Anaesthesia and Obstetrics; $\downarrow$ St Thomas' Hospital Fetal Health Research Group, King's College London, UK

Introduction Epidural analgesia for labour is associated with increased obstetric intervention [1]. Ambulatory techniques may increase the rate of spontaneous vaginal delivery.

Methods Over 2100 primiparous women, requesting epidural analgesia, were randomised to receive boluses of $0.25 \%$ bupivacaine (Traditional) or combined spinal epidural (CSE) or low-dose infusion (LDI). The latter two utilized $0.1 \%$ bupivacaine with fentanyl $2 \mu \mathrm{g} \mathrm{mL}^{-1}$ to preserve the potential for ambulation.

Intrapartum data collection included mode of delivery and all women were interviewed after delivery to assess pain relief.

A computer randomization error led to recruitment of 1054 women with an unequal age distribution (C.O.M.E.T. 1). A second sample of the same size, with an equal age distribution, was therefore recruited (C.O.M.E.T. 2). This is presented as the primary data set. Age standardized analysis of C.O.M.E.T. 1 will also be considered.

Results Both ambulatory techniques were found to be associated with a significantly higher incidence ( $P$ $<0.05$ ) of spontaneous vaginal delivery (CSE: $43 \%$, LDI: $43 \%)$ compared with traditional epidural analgesia (35\%). Maternal reports of pain relief after epidural insertion demonstrated no difference between techniques. 


\section{Reference}

1 The Cochrane Library, Issue 4, 1999.

The C.O.M.E.T. Study Group, UK:

${ }^{*}$ S. Bharmal; †D. Bick; †G. Cooper; †L. Crewe; ${ }^{*}$ C. D. Elton; $\dagger$ H. Garston; †L. Gold; ${ }^{*}$ A. W. Halligan; ${ }^{*}$ N. Hickman; $\Varangle$ W. Hussain; †M. Lewis; †C. MacArthur; ${ }^{*} A$. E. May; $\doteqdot$ †. A. S. Moore; ${ }^{*}$ M. Patterson; $†$ A. Shennan; ${ }^{*}$ P. Squire; $\dagger J$. Whyte; †M. J. A. Wilson

\section{ABSTRACT NO. 51}

Comparison of two teaching methods for continuous medical education in anaesthesia

E. Carrero, C. Gomar, W. Penzo, N. Fábregas, A. Villalonga and J. Castillo

FEEA Regional Center of Cataluña, Department of Anesthesiology and Psychology, Hospital Clinic University of BarceIona, Barcelona, Spain

Introduction Continuous medical education (CME) improves quality of medical care [1]. As opposed to clinical or experimental studies, educational investigations are scarce. This study was designed to evaluate the effectiveness of two different teaching methods of CME in anaesthesia.

Methods Fifty-nine practising anaesthesiologists, registered in a FEEA course [2] (Regional Center of Cataluna) on February 2000, were randomly assigned to receive either a didactic (Group I) or interactive CME teaching session (Group II) on air embolism (EA). Before and post-CME sessions, two different case report tests were carried out to assess anaesthesiologists' ability to detect: (a) issues related to EA (b) differential diagnosis (c) monitoring and (d) treatment. SPSS for Microsoft Windows was used for statistical analysis.

Results No difference in preteaching knowledge was detected between groups. The ability to detect issues related to $E A$ did not change after CME sessions. However, inclusion of EA in differential diagnosis (post-teaching test) was more frequent in group II $(100 \%)$ than in group $I(77.8 \%)(P<0.05)$. Precordial Doppler monitoring to diagnose EA was considered by only $2 \%$ of the anaesthesiologists in the preteaching test. This percentage increased significantly in the post-teaching test $(58 \%)$ without differences between groups. After CME sessions, there was an improve- ment in the treatment modalities suggested. A more detailed analysis of these data showed that, in postteaching test, the interactive group followed a better algorithm treatment $(P<0.05)$.

Conclusions (1) CME increased knowledge about EA monitoring (precordial Doppler) and the treatment for EA. (2) The interactive educational method improved anaesthesiologists' performance.

\section{References}

1 Davis DA, Thomson MA, Oxman AD, Haynes RB. Evidence for the effectiveness of CME. A review of 50 randomized controlled trials. JAMA 1992; 268: 1111-1117.

2 Scherpereel P. Foundation for European Education in Anaesthesioogy. Fondation Européenne d'Enseignement en Anésthesiologie. Eur J Anesthesiol 2000; 17: 75-76.

\section{ABSTRACT NO. 52}

\section{Does smoking have an influence on PONV?}

D. Ionescu, C. Badescu, D. Maican and I. Acalovschi

Department of Anaesthesia, University of Medicine and Pharmacy, Cluj-Napoca, Romania

Introduction The purpose of this study was to evaluate the influence of smoking on the incidence of postoperative nausea and vomiting (PONV) in patients undergoing laparoscopic cholecystectomy.

Methods Seventy patients who underwent laparoscopic cholecystectomy under general anaesthesia, were divided into two groups: group $1(n=40)$ of nonsmokers and group $2(n=30)$ of patients with a history of smoking. In each group, the induction agent was propofol for half of the patients and thiopental for the others. Postoperatively, nausea, retching, vomiting, the degree of pain (on a visual analogue scale) and analgesic requirements were assessed for $24 \mathrm{~h}$.

Results PONV occurred in 30 patients (75\%) in group 1 compared with 11 patients $(36.6 \%)$ in group $2(P<$ $0.05)$. The degree of pain was significantly less in the smokers group (group 2) as compared with the nonsmokers (group 1) $(P=0.0013)$. The analgesic requirements were also significantly reduced in the smokers group.

Conclusion We conclude that the history of smoking significantly reduced PONV in patients undergoing laparoscopic cholecystectomy. Moreover, smoking 
reduced the degree of pain and the analgesic requirements. Despite the better postoperative condition of patients with a history of smoking we would like to emphasise that our study is not advertising for smoking.

\section{Reference}

1 Cohen MM, Duncan PG, DeBoer DP, Tweed W A. The postoperative interview: assessing risk factors for nausea and vomiting. Anesth Analg 1994; 78: 7-16.

\section{ABSTRACT NO. 53}

Choice of induction agent does not affect incidence of postoperative nausea and vomiting

E. Basto, F. Mourey, L. Jacob and B. Eurin

University Hospital of Saint-Louis, Paris, France

Introduction Subhypnotic doses of propofol (P) possess direct antiemetic properties [1] and total intravenous anaesthesia using $P$ reduce the incidence of postoperative nausea and vomiting (PONV) [2]. But $P$ used only as an induction agent of anaesthesia (IAA) is not protective against PONV [2]. However, most anaesthesiologists believe the opposite [3]. This confusion was increased by one retrospective report [4]. This study was performed to compare the incidence of PONV according to the IAA used.

Methods Data from patients who underwent cervical endocrine surgery during a 3-yr period (1997-1999) were retrospectively analysed. The following parameters were recorded: age, gender, Quetelet Index (QI), ASA score, IAA, PONV reported and treated in the postanaesthesia care unit (constant monitoring for two hours). We compared groups according to the IAA used, propofol (P) vs. thiopental (T) vs. etomidate $(E)$, and according to the occurrence of PONV (PONV+ vs. PONV-). Patients with preoperative documentation of PONV were excluded. Statistical analysis was performed with a $\chi^{2}$ test and multivariate logistic regression.

Results Data of 1000 patients were included. PONV+ $(25.5 \%)$ and PONV- $(74.5 \%)$ were comparable in terms of age $(49.8 \pm 14$ vs. $51 \pm 16)$, Ql $(25.4 \pm 5$ vs.
$24.9 \pm 5)$, ASA $(1.8 \pm 0.7$ vs. $1.9 \pm 0.8)$, IAA $(P=0.67)$ but were different for gender ratio $(F=75 \%, M=25 \%, P$ $=0.03$ ). $\mathrm{P}$ and $\mathrm{T}$ were similar for all considered parameters. $\mathrm{E}$ was comparable to $\mathrm{P}$ and $\mathrm{T}$ for all parameters, except age and ASA, which were not considered as risk factors of PONV in our study (Table 1). Posologies of IAA were: $P(2.7+1.16 \mathrm{mg}$ $\left.\mathrm{kg}^{-1}\right), \quad \mathrm{T}\left(5.3+2.14 \mathrm{mg} \mathrm{kg}^{-1}\right)$ and $\mathrm{E}(0.36+0.28 \mathrm{mg}$ $\left.\mathrm{kg}^{-1}\right)$.

Conclusion In cervical endocrine surgery, induction agent of anaesthesia does not affect the incidence of PONV.

Table 1. Effects of three i.v. anaesthetics on postoperative nausea and vomiting

\begin{tabular}{llll}
\hline & Propofol & Thiopental & Etomidate \\
\hline$n$ & 314 & 477 & 209 \\
PONV (\%) & 27.8 & 24.1 & 24.3 \\
Age (years) & $49.9 \pm 15$ & $50.8 \pm 15$ & $59.3 \pm 16^{*}$ \\
Ol & $24.8 \pm 6$ & $24.7 \pm 5$ & $25.4 \pm 6$ \\
ASA & $1.71 \pm 0.7$ & $1.75 \pm 0.6$ & $2.57 \pm 0.7^{*}$
\end{tabular}

${ }^{*} P<0.05$.

\section{References}

1 Borgeat A, Wilder-Smith OHG, Saiah M, Rifat K. Subhypnotic doses of propofol possess direct antiemetic properties. Anesth Analg 1992; 74: 539-541.

2 Gan TJ, Ginsberg B, Grant AP, Glass PSA. Double-blind, randomised comparison of ondansetron and intraoperative propofol to prevent postoperative nausea and vomiting. Anesthesiology 1996; 85: 1036-1042.

3 Eberhart LH, Morin AM, Felbinger TW, Falkner Y, Georgieff $M$, Seeling $W$. Postoperative nausea and vomiting. Propofol or thiopentone: does choice of induction agent affect outcome? Anaesthesiol Intensivmed Notfallmed Schmerzth 1998; 33: 545-551.

4 Myles PS, Hendrata N, Bennett AM, Langley M, Buckland MR. Postoperative nausea and vomiting. Propofol or thiopentone: does choice of induction agent affect outcome? Anaesth Intensive Care 1996; 24: 355-359. 


\section{ABSTRACT NO. 54}

\section{A comparison of the laryngeal views obtained during conventional and balloon laryngoscopy}

S. Mentzelopoulos, C. Romana, D. Corolanoglou, M. Tzoufl, P. Giannakopoulos and E. Karamichali Evangelismos General Hospital, Athens, Greece

Introduction Balloon laryngoscopy, a new laryngoscopic technique comprising the inflation of a balloon placed on a curved blade, has been reported to facilitate difficult airway management [1]. In the present study, we tested the hypothesis that balloon laryngoscopy might result in an improved laryngeal view relative to conventional regardless of the preoperative simplified airway risk index (SARI) score [2].

Methods Anaesthesia was induced in 17 ASA I-II elective surgical patients with a SARI-score of 0-7 [2]; cis-atracurium was used for neuromuscular blockade. After the disappearance of all four twitches from the train of four, laryngoscopy was performed changing between a standard curved blade \#4 and a modified curved blade \#4 carrying a $0.19-\mathrm{cm}$ (6F) Fogarty catheter. The patient's head was immobilized in the standard intubating position [3]. The angle of the laryngoscope handle relative to horizontal was kept at $15^{\circ}$ to avoid any levering motion of the blade. The balloon laryngoscopy technique included placement of the modified blade-tip into the vallecula, inflation of the Fogarty catheter balloon with $1.5-2.0 \mathrm{~mL}$ of air, and anterior-elevation of the modified blade. The laryngoscopic findings were recorded with a SONY-TRV 310-E camcorder, which was aligned to the axis of the blade's light source. The recorded images that contained the best laryngoscopic views were grabbed with Canopus-raptor-video and their size adjusted according to the magnification factors ensuing during each laryngoscopy. The perimeters of the exposed laryngeal aperture-portions were drawn in Photoshop 5.0 and their surface areas determined with Corel Draw 5.0 and Autocad 2000. The Kolmogorov-Smirnov test revealed that the distributions of the data obtained during both laryngoscopic techniques were Gaussian, and the surface area values of the exposed laryngeal aperture-portions were compared with Student's paired $t$-test. Significance was accepted at $P<$ 0.05 .

Results Balloon laryngoscopy resulted in significantly greater laryngeal exposure relative to conventional $\left(1.23 \pm 0.751 \mathrm{~cm}^{2}\right.$ vs. $0.921 \pm 0.584 \mathrm{~cm}^{2}, \quad P=$ 0.0043).

Conclusion Balloon laryngoscopy results in improved laryngeal view when compared to conventional laryngoscopy.

\section{References}

1 Mentzelopoulos SD, Tsitsika MV, Karamichali EA. Difficult airway management with balloon inflation. Anesth Analg 1999; 88: 1425-1426.

2 El-Ganzouri AR, McCarthy RJ, Tuman KJ, Tank EN, Ivavkovitch $A D$. Preoperative airway assessment: predictive value of a multivariate risk index. Anesth Analg 1996; 82: 1197-1204.

3 Horton WA, Fahy L, Charters P. Defining a standard intubating position using 'angle finder'. Br J Anaesth 1989; 62: 6-12. 